\title{
The aryl hydrocarbon receptor reduces LC3II expression and controls endoplasmic reticulum stress
}

Necola Guerrina ${ }^{1,2}$, Noof Aloufi ${ }^{1,2}$, Fangyi Shi ${ }^{1,2}$, Kashmira Prasade ${ }^{1}$, Caitlin Mehrotra ${ }^{4}$, Hussein Traboulsi ${ }^{1,3}$, Jason Matthews ${ }^{5,6}$, David H. Eidelman ${ }^{1,3}$, Qutayba Hamid ${ }^{1,3,7}$ and Carolyn J. Baglole $1,2,3,4$

${ }^{1}$ Research Institute of the McGill University Health Centre, Departments of ${ }^{2}$ Pathology, ${ }^{3}$ Medicine, ${ }^{4}$ Pharmacology and Therapeutics, McGill University; ${ }^{5}$ Department of Nutrition, University of Oslo, Oslo, Norway; ${ }^{6}$ Department of Pharmacology \& Toxicology, University of Toronto, Toronto Canada; ${ }^{7}$ College of Medicine, University of Sharjah, United Arab Emirates.

Correspondence and requests for materials should be addressed to:

Carolyn J. Baglole

1001 Decarie Blvd (EM22248)

Montreal, Quebec H4A3J1

Telephone: (514) 934-1934 ext. 76109

E-mail: Carolyn.baglole@mcgill.ca

Running Title: AhR attenuates ER stress 


\begin{abstract}
The aryl hydrocarbon receptor (AhR) is a ligand-activated transcription factor whose physiological function is poorly understood. The AhR is highly expressed in barrier organs such as the skin, intestine and lung. The lungs are continuously exposed to environmental pollutants such as cigarette smoke (CS) that can induce cell death mechanisms such as apoptosis, autophagy and endoplasmic reticulum (ER) stress. CS also contains toxicants that are AhR ligands. We have previously shown that the AhR protects against apoptosis, but whether the AhR also protects against autophagy or ER stress is not known. Using cigarette smoke extract (CSE) as our in vitro surrogate of environmental tobacco exposure, we first assessed the conversion of LC3I to LC3II, a classic feature of both autophagic and ER stress-mediated cell death pathways. LC3II was elevated in CSE-exposed lung structural cells (mouse lung fibroblasts [MLFs], MLE12 and A549 cells) when AhR was absent. However, this heightened LC3II expression could not be explained by increased expression of key autophagy genes (Gabarapl1, Beclin-1, Lc3b), upregulation of upstream autophagic machinery (Atg5-12, Atg3) or by impaired autophagic flux, suggesting that LC3II may be autophagy-independent. This was further supported by the absence of autophagosomes in $A h r^{-/}$lung cells. However, $A h r^{-/}$lung cells had widespread ER-dilation, elevated expression of the ER stress markers CHOP and GADD34 and an accumulation of ubiquitinated proteins. These findings collectively illustrate a novel role for the AhR in attenuating ER stress by a mechanism that may be autophagy-independent.
\end{abstract}




\section{INTRODUCTION}

The aryl hydrocarbon receptor (AhR) is a ligand-activated transcription factor that belongs to the basic helix loop helix PER-ARNT-SIM (bHLH/PAS) family of regulatory proteins (64). Although ubiquitously-expressed throughout the body, AhR expression is highest in first-line defense organs such as the lung, gut, skin, and liver (25). Historically, the AhR is best-known for its ability to mediate the detrimental effects of the man-made toxicant 2,3,7,8-tetrachlorodibenzop-dioxin (TCDD; dioxin) $(9,26,57)$. In the absence of ligand, the AhR is found in the cytoplasm complexed with chaperone proteins (72). After ligand binding, the AhR translocates to the nucleus and forms a heterodimer with the AhR nuclear transporter (ARNT). This AhR•ARNT complex binds to DNA sequences termed the dioxin response element (DRE), initiating the transcription of genes such as cytochrome P450 (CYP) CYP1A1. Persistent activation of the AhR pathway by dioxin is associated with toxic responses (12). There is also a second AhR pathway called the "non-genomic" or "DRE-independent" AhR pathway because there is little-to-no DRE binding following activation. This AhR pathway may contribute to non-xenobiotic functions of the AhR such as cholesterol biosynthesis (90), cell migration (93) and cell survival $(33,79)$.

Thus, in recent years the AhR has emerged as an important regulator of cellular processes independent of dioxin exposure $(8,62,84,96)$. Perturbations in these processes can lead to prevalent diseases such as chronic obstructive pulmonary disease (COPD) and lung cancer, diseases that are largely caused by exposure to cigarette smoke (CS). CS is also a mixture of gases and particulate matter (PM) composed of metals (iron, nickel), gases, biological agents (endotoxins) and organic chemicals such as polychlorinated dibenzodioxins ([PCDDs] and polycyclic aromatic hydrocarbons $[\mathrm{PAHs}])(21,29,65,94)$. Many of these organic chemicals are ligands of the $\operatorname{AhR}(76,95)$. We have previously shown that the AhR protects the lung against 
some of the deleterious the effects of CS, including attenuation of apoptosis in lung structural cells (75). While it is postulated that loss of lung cells due to apoptosis contributes to diseases such as COPD, other cell death mechanisms are also important, and likely work in an inter-dependent manner. These other cell death mechanisms may include autophagy, cytoplasmic vacuolization death and paraptosis, all of which are associated with endoplasmic reticulum (ER) stress (20, 40, 89, 97). ER stress is caused by the accumulation of misfolded protein aggregates in the ER lumen, leading to the initiation of a three-branched signaling cascade collectively referred to as the unfolded protein response (UPR). Exposure to toxicants such as CS can induce excessive or prolonged ER stress that may render the UPR insufficient to restore homeostasis, such that the 'pro-death' arm of the ER stress response dominates (82). This pro-death arm depends on the upregulation of the transcription factor C/EBP homologous protein (CHOP) $(46,53,108)$, which then induces apoptosis and/or autophagy $(30,50,89)$. Autophagy involves the cytoplasmic uptake of damaged proteins, substrate and organelles by autophagic vesicles (autophagosomes) and their subsequent lysosomal degradation (28). Exposure to CS causes an accumulation of autophagosomes within lung structural cells, leading to cell death $(19,61)$.

Another feature common to both ER stress and autophagy is the processing of microtubuleassociated protein 1 light chain 3 (LC3), from the unconjugated isoform (LC3I) to the autophagosomal membrane-bound and phosphatidylethanolamine (PE)-conjugated isoform (LC3II). This post-translational processing of LC3 is critical for autophagosome maturation (63). Thus, LC3 is conventionally regarded as a marker of autophagy (45). However, LC3 processing can also be autophagy-independent and can occur during ER stress-mediated cell death mechanisms such as cytoplasmic vacuolation death and paraptosis $(40,44,88)$. These autophagyindependent cell death mechanisms are characterized by the absence of autophagosomes and a 
failure to increase the expression of other autophagy markers.

Our knowledge of the mechanisms controlling these various forms cell death remains incompletely understood. We hypothesize that the AhR may be an important regulator of cell survival in the harsh environment of the lung, and thus be capable of attenuating alternative cell death mechanisms- including autophagy and ER stress- in lung structural cells. These lung structural cells include alveolar epithelial cells and fibroblasts, which are responsible for gas exchange and the synthesis of the extracellular matrix necessary to maintain lung structure, respectively. We have used CS as a relevant environmental toxicant to understand how the AhR controls lung structural cell death. Using an in vitro model of CS exposure together with AhRdeficient/knock-down lung cells, we show that the AhR attenuates ER stress by a mechanism that is independent of autophagy, but one that involves LC3 processing. Our data support a critical role for the AhR in promoting lung structural cell survival. 


\section{MATERIALS AND METHODS}

Chemicals- All chemicals were purchased from Sigma-Aldrich (St. Louis, MO) unless otherwise indicated. Bafilomycin A1 was purchased from Enzo Life Sciences (Farmingdale, NY). Actinomycin D (ActD) was purchased from Biomol (Plymouth Meeting, PA). CH-223191 (1Methyl-N-[2-methyl-4-[2-(2-methylphenyl) diazenyl] phenyl-1H-pyrazole-5-carboxamide) is from Tocris Bioscience (Minneapolis, MN).

Cell Culture- Primary lung fibroblasts were generated from $A h r$ wild-type $\left(A h r^{+++}\right), A h r$ heterozygous $\left(A h r^{+-}\right)$and $A h r$-deficient $\left(A h r^{-/}\right)$male and female C57BL/6 mice (Jackson Laboratory, Bar Harbor, ME) as previously described $(6,105)$. A breeding scheme of heterozygous $A h r^{+/}$to $A h r^{-/}$mice are used, rendering mice of the $A h r^{+/}$genotype as littermate controls. $A h r^{+/-}$ mice are phenotypically indistinguishable from wild-type $\left(A h r^{+/+}\right)$mice and are often used as controls when examining the physiological, pathophysiological and toxicological parameters of the $\operatorname{AhR}(14,31,81,85,87)$. Moreover, $A h r^{+/+}$or $A h r^{+/}$mice/cells do not exhibit any difference in the ability to be activated by AhR ligands or cigarette smoke and are used interchangeably as AhR-expressing mice/cells $(5,24,91,105)$, rendering cells derived from $\mathrm{Ahr}^{+/-}$mice as suitable controls for this study. Therefore, $A h r^{+/}$cells were utilized as control cells unless otherwise indicated. Verification of AhR protein levels in the $A h r^{+/-}$to $A h r^{-/}$cells used for these experiments is in Fig. S1 (available at: 10.6084/m9.figshare.12830321). Lung fibroblasts were also generated from novel lineages of mice harboring either a mutant AhR that is incapable of translocating to the nucleus $\left(A h r^{n l s / n l s}\right)$ or binding to DNA (referred to hereafter as $\left.A h r^{d b d / d b d}\right)(12,13)$, both a kind gift of Dr. Chris Bradfield (University of Wisconsin); lung fibroblasts from littermate heterozygotes $\left(A h r^{D B D / B 6}\right)$ are used as corresponding controls (105). MLE12 cells, a distal bronchiolar and 
alveolar epithelial cell line (ATCC, Manassas, VA) (101), were cultured in DMEM-F12 as described (105). A549 cells were used to generate A549-AhR ${ }^{\mathrm{ko}}$ cells using a zinc finger nuclease (ZFN) technology targeting the AhR; these cells were cultured in DMEM as described $(1,34)$. AhR deletion and lack of a functional response to TCDD were previously verified (34). All cells were maintained at $37^{\circ} \mathrm{C}$, incubated in humidified $5 \% \mathrm{CO}_{2}, 95 \%$ air and all experiments were conducted following $12-24 \mathrm{~h}$ in serum free media.

Preclinical Cigarette Smoke (CS) Model- Age and gender-matched $A h r^{-/}$and $A h r^{+-}$mice were exposed to CS using a whole-body exposure system (InExpose; SCIREQ Inc., Montreal, Canada) $(24,91,105)$. Briefly, mice were exposed to research cigarettes (3R4F; University of Kentucky, Lexington, KY) for two, 1-hr CS-exposures/day for 5 days/week. Experiments were performed in duplicate with 5-10 mice per group. All animal procedures were approved by the McGill University Animal Care Committee (Protocol Number 5933) and were carried out in accordance with the Canadian Council on Animal Care.

Preparation of Cigarette Smoke Extract (CSE)- Research grade cigarettes (3R4F) with a filter were obtained from the Kentucky Tobacco Research Council (Lexington, KT) and CSE was generated as previously described $(4,5,7,16)$. Briefly, smoke from one cigarette was bubbled into $10 \mathrm{ml}$ of serum free-media and subsequently passed through a $0.45 \mu \mathrm{m}$ sterile filter (25-mm Acrodisc; Pall Corp., Ann Arbor, MI). An optical density of $0.65(320 \mathrm{~nm})$ was considered to represent $100 \%$ CSE. This CSE preparation was diluted to $2 \%$ in the appropriate serum free media.

Imaging Flow Cytometry-Cells were fixed with 4\% paraformaldehyde (PFA) for 20 min, washed 
and resuspended in PBS with $0.2 \%$ BSA (Fisher BioReagents) at $4{ }^{\circ} \mathrm{C}$ overnight. Cells were then permeabilized using 1:10 Perm/Wash buffer (BD Biosciences, Mississauga, Ontario). Anti-LC3B mAB (1:100; MBL International, Woburn MA) was then added to the samples for 30 min. Cells were next incubated with Alexa-Flour 488 goat anti-mouse (1:1000; Invitrogen) secondary antibody for $30 \mathrm{~min}$. Cells were then washed and re-suspended in PBS. Images were acquired using the ImageStreamX (Amnis, Seattle, Washington). Samples were gated to remove debris, and at least 10,000 events per sample were then analyzed using the IDEAS 6.1 software. The bright detail intensity (BDI) was used to evaluate LC3 punctae.

Transfection- MLE12 cells were transiently transfected with 60 nM siRNA against AhR (Santa Cruz) or non-targeting control siRNA (Santa Cruz) according to the manufacturer's instructions. Six hours after the transfection cells were switched to DMEM-F12 medium containing antibiotics/ antimycotics and treated with CSE for 3-24h.

Western Blot- Total cellular protein was prepared using RIPA lysis buffer supplemented with a protease inhibitor cocktail (Roche Diagnostics, Germany) and protein quantitation performed with the bicinchoninic acid (BCA) method (Pierce, Rockford, IL). Five to forty $\mu \mathrm{g}$ of cellular proteins were fractionated on SDS-PAGE gels and electroblotted onto immunoblot polyvinylidene difluoride (PVDF) membrane (Bio-Rad Laboratories, St. Laurent, QC, Canada). Incubation with a primary antibody (Table 1) followed by the HRP-conjugated secondary antibody was used to assess changes in protein levels. Protein levels were visualized by enhanced chemiluminescence (ECL) and detected using a gel documentation system (Bio-Rad). Densitometry was performed using ImageJ. Images of uncropped blots are in Fig. S2. 
Analysis of Gene Expression- Total RNA was isolated from media or CSE-treated cultured cells using a Qiagen miRNeasy kit (Qiagen Inc., Hilden, Germany). RNA samples were diluted to a concentration of $10 \mathrm{ng} / \mu \mathrm{l}$. Following dilution, reverse transcription of total RNA was carried out in a $25-\mu 1$ reaction mixture by iScript II $^{\mathrm{TM}}$ Reverse Transcription Supermix (Bio-Rad Laboratories, Mississauga, $\mathrm{ON}$, Canada) at $25^{\circ} \mathrm{C}$ for $5 \mathrm{~min}$, at $42^{\circ} \mathrm{C}$ for $30 \mathrm{~min}$ and at $85^{\circ} \mathrm{C}$ for $5 \mathrm{~min}$. Quantitative PCR (qPCR) was performed with $1 \mu \mathrm{l}$ cDNA from the media and CSE-treated cultured cells and $0.5 \mu \mathrm{M}$ primers added in Ssofast ${ }^{\mathrm{TM}}$ Eva Green ${ }^{\circledR}$ Super-mix (Bio-Rad). PCR amplification was performed using a CFX96 Real-Time PCR Detection System (Bio-Rad) as described (105). Gene expression was analyzed using the ${ }^{\Delta \Delta} \mathrm{Ct}$ method following normalization to the housekeeping gene $\beta$-actin. Primer sequences utilized for qPCR are listed in Table 2. Xbp- 1 mRNA splicing was assessed by PCR, which was carried out in a $25 \mu 1$ reaction mixture consisting of $1 \mu \mathrm{l}$ of $10 \mu \mathrm{M}$ forward mouse $X b p-1$ primer, $1 \mu \mathrm{l}$ of $10 \mu \mathrm{M}$ reverse mouse $X b p-1$ primer, $2 \mu l$

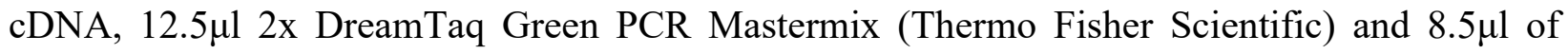
nuclease free water at $95^{\circ} \mathrm{C}$ for $15 \mathrm{sec}, 50^{\circ} \mathrm{C}$ for $30 \mathrm{sec}$, and $72^{\circ} \mathrm{C}$ for $34 \mathrm{sec}$ for a total of $35 \mathrm{cycles}$. Samples were then run using gel electrophoresis on a 3\% agarose gel for $1.5 \mathrm{~h}$. The primers utilized for $X b p-1$ PCR flank the 26-nucleotide intron that is removed following IRE1 $\alpha$ activation to yield sXbp-1; the sequence was: (forward) CCT TGT GGT TGA GAA CCA and (reverse) GTG TCA GAG TCC ATG GGA(32).

Transmission Electron Microscopy (TEM)- Following treatment with media or 2\% CSE for 8h, $A h r^{-/}$and $A h r^{+/-}$MLFs were trypsinized and centrifuged to form a pellet. Supernatant was removed and the pellets were fixed in 2.5\% glutaraldehyde (Electron Microscopy Sciences, Hatfield, PA) 
overnight at $4^{0} \mathrm{C}$ followed by incubation with $1 \%$ osmium tetroxide (Mecalab, Montreal, QC, Canada) and $1.5 \%$ potassium ferrocyanide (Fisher Scientific, Ottawa, ON, Canada) for $1 \mathrm{~h}$ at $4^{\circ} \mathrm{C}$. Cells were washed and dehydrated in a graded series of ethanol/deionized water, infiltrated with a 1:1 and 3:1 Epon 812 (Mecalab, Montreal, QC, Canada) ethanol mixture for 30 min followed by 100\% Epon 812 for $1 \mathrm{~h}$. Finally, the cells were embedded in fresh $100 \%$ Epon 812 and left to polymerize overnight at $60^{\circ} \mathrm{C}$. Blocks were cut in $100 \mathrm{~nm}$ ultrathin sections with an Ultracut $\mathrm{E}$ ultramicrotome (Reichert Jung, Cambridge, UK) and transferred onto 200-mesh copper grids (Electron Microscopy Sciences, Hatfield, PA). Sections were post-stained first with 4\% aqueous uranyl acetate (Electron Microscopy Sciences, Hatfield, PA) followed by Reynold's lead citrate (Fisher Scientific, Ottawa, ON, Canada). Samples were imaged with a FEI Tecani-12 transmission electron microscope (FEI, Hillsboro, OR) operating at an accelerating voltage of $120 \mathrm{kV}$ equipped with an XR-80C AMT, 8-megapixel CCD camera.

Determination of Chop mRNA stability $-A h r^{-/}$and $A h r^{+/-}$MLFs were treated with $2 \%$ CSE for $2 \mathrm{~h}$, followed by treatment with $1 \mu \mathrm{g} / \mathrm{mL}$ ActD for $0.5 \mathrm{~h}, 2 \mathrm{~h}$ and $6 \mathrm{~h}$. ActD treatment times were chosen based on the half-life of Chop mRNA, which ranges between $0.5 \mathrm{~h}$ and $5 \mathrm{~h}(11,52,77)$. Following treatments, Chop mRNA expression was assessing using qPCR as described above.

Statistical Analyses- Statistical analysis was performed using Prism 6-1 (La Jolla, CA). A two-way analysis of variance (ANOVA) followed by a Newman-Keuls multiple comparisons test. In all cases, a p-value $<0.05$ is considered statistically significant. 


\section{RESULTS}

The AhR attenuates LC3II in lung structural cells by a mechanism that requires AhR nuclear localization and DRE binding- Changes in LC3II is a feature of both autophagic and ER stressmediated cell death. Therefore, we first analyzed LC3II expression by western blot. In Ahr-- MLFs, there was a significant increase in LC3II at the basal level and in response to CSE (Fig. 1A). Similarly, AhR knock-down MLE12 cells exhibited a significant increase in LC3II in response to CSE relative to cells transfected with the control siRNA (siCtrl) (Fig. 1B and 1C). Finally, we evaluated LC3II in the human alveolar epithelial cell line A549, whereby AhR expression was eliminated by zinc finger nuclease technology (1). In both untreated- and CSE-exposed A549$\mathrm{AhR}^{\mathrm{ko}}$ cells, LC3II was significantly higher compared to the A549 Parent cells (Fig. 1D). Using ImageStream ${ }^{\circledR}$, we analyzed cellular LC3 punctae using the bright detail intensity (BDI). In accordance with previously published findings, LC3BDI-high (defined as cells with a LC3 BDI greater than $\sim 3 \mathrm{e} 4$ ) is reflective of cells with numerous, bright LC3 punctae, and thus heightened LC3 expression (23). A549-AhR ${ }^{\mathrm{ko}}$ cells had increased LC3 punctae as supported by a higher proportion of LC3 BDI-high cells (Fig. 1E). CSE-treated A549-AhR ${ }^{\mathrm{ko}}$ also showed the highest proportion of LC3 BDI-high cells (70.3\%; Fig. 1E). Finally, we analyzed LC3II by western blot in whole lung homogenates from $A h r^{-/}$and $A h r^{+/}$mice exposed to CS for 8 weeks. LC3II levels were elevated in the lungs of the CS-exposed $\mathrm{Ahr}^{-/}$mice relative to CS-exposed $\mathrm{Ahr} r^{+/}$mice (Fig. $1 \mathrm{~F})$.

We next wondered whether the mechanism through which the AhR controlled LC3IIIIwould require translocation of AhR to the nucleus and subsequent binding to the DRE. To evaluate this, we utilized MLFs from $A h r^{n l s h l s}$ or $A h r^{d b d / d b d}$ mice. There was an increase in LC3II in both $A h r^{n l s} n l s s$ 
(Fig. 2A) and $A h r^{d b d / d b d}$ (Fig. 2B) MLFs at basal levels as well as after CSE exposure. Collectively, these data support that the AhR controls basal LC3II in lung structural cells by a mechanism that requires both nuclear localization and DRE binding.

Upregulation of LC3II in AhR-deficient lung cells is not due to impaired autophagic flux- LC3II processing is well-recognized as a hallmark of autophagy. Therefore, we next sought to determine if the increased LC3II in CSE-treated AhR-deficient cells was due to impairment in autophagic flux. We first evaluated the expression of $\mathrm{p} 62$, which targets proteins for degradation through autophagy (49). Although CSE increased p62 protein expression in the $A h r^{+/-}$MLFs, there was no significant difference in p62 expression between CSE-exposed $A h r^{-/}$and $A h r^{+/}$cells (Fig. 3A). There was also no difference in p62 expression between CSE-treated A549-AhR ${ }^{\mathrm{ko}}$ and AhR Parent cells (Fig. 3B). To more firmly establish whether the AhR regulates autophagic flux, we utilized Bafilomycin A1, an inhibitor of autophagosome-lysosome fusion (102). We assessed LC3II protein in A549-AhR ${ }^{\mathrm{ko}}$ and AhR Parent cells treated with CSE in the presence or absence of Bafilomycin A1. Although Bafilomycin A1 induced a significant increase in LC3II expression, LC3II in the untreated and CSE-treated A549-AhR ${ }^{\mathrm{ko}}$ cells was significantly less than when in the presence of Bafilomycin A1 (Fig. 3C). However, there was also no difference in LC3II expression between A549-AhR ${ }^{\mathrm{ko}}$ and AhR Parent cells treated with Bafilomycin A1. Taken together, these results suggest that impairment in autophagic flux does not likely explain the heightened LC3II in AhR-deficient cells.

Increased LC3II in AhR-deficient lung structural cells is not due to an upregulation of upstream autophagy-related proteins- Given that LC3II was elevated in the absence of AhR, we reasoned 
that this might be accompanied by an increase in the upstream autophagic markers ULK1, Atg512 and Atg3. Of these, only ULK1 expression appeared to change in response to CSE in $A h r^{+/-}$ MLFs (Fig. 4A- left panel) but this this not reach statistical significance. There was also no significant difference in the expression Atg5-12 or Atg3 (Fig. 4B-C-left panels). Similar results were obtained in A549 cells, where there was no significant difference in the expression of these autophagy-related proteins either in response to CSE or based on AhR expression (Fig. 4A-Cright panels). Collectively, elevated LC3II in AhR-deficient cells cannot be explained by changes in upstream autophagic machinery.

The AhR does not control the expression of autophagic genes- The canonical AhR pathway involves the translocation of the $\mathrm{AhR}$ to the nucleus and subsequent alterations in gene expression due to DRE-dependent transcription $(12,57)$. We therefore reasoned that the AhR attenuation of LC3II may be related to its functions as a transcription factor. Thus, we chose for analysis autophagic markers known to be regulated at the mRNA level, which included Gabarapl1, Beclin1 and $L c 3 b$ (58). However, there was no significant difference in expression of Gabarapll (Fig. 5A), Beclin-1 (Becnl) (Fig. 5B) or Lc3b mRNA (Fig. 5C) between the $A h r^{-/-}$and $A h r^{+/-}$MLFs (Fig. 5- left panels) or between A549-AhR ${ }^{\mathrm{ko}}$ and A549 Parent cells (Fig. 5-right panels). To ensure that the lack of induction in these autophagy genes was not due to impaired AhR activation, we assessed levels of Cyplal mRNA, whose induction by CSE is dependent on the AhR (105). These data show that in both MLFs and A549 cells, there was significant upregulation in Cyplal mRNA only in CSE-treated AhR-expressing cells (Fig. 5D). The lack of induction of Cyplal mRNA also confirms absence of AhR protein in the $A h r^{-/-}$MLFs as well as the A549-AhR ko cells. Therefore, we conclude that the AhR does not regulate the expression of these autophagy-related genes 
despite strong activation of the AhR by CSE.

AhR deficiency results in ER stress- In an attempt to determine if the elevated LC3 processing in $A h r^{-/}$MLFs was indeed associated with autophagy, we assessed transmission electron micrographs (TEMs) for the presence of autophagosomes, a technique/read-out considered to be the gold standard for validating autophagy (42). However, there was a distinct absence of an accumulation of autophagosomes in the $A h r^{-/}$MLFs, although some autophagosomes (black arrowheads) were observed (Fig. 6A and Fig. S3). What was striking was the existence of extensive dilation in the rough ER (white arrowheads) only in the $A h r^{-/}$MLFs, which was further exacerbated following exposure of these cells to CSE (Fig. 6A). This is a morphological hallmark of ER stress that occurs in response to an accumulation of misfolded proteins (82). Other features of ER stress-mediated cell death include the accumulation of ubiquitinated proteins, UPR activation and the upregulation of UPR targets. We also observed a dramatic increase in ubiquitinated proteins in $A h r^{-/}$MLFs that was further exacerbated following CSE exposure (Fig. 6B). These data were suggestive of alteration in ER stress that was aggravated by AhR deficiency.

Therefore, we next assessed the expression of upstream proteins involved in the three branches of the UPR signaling cascade. These included the phosphorylated form of the eukaryotic translation initiation factor $2 \alpha$ (p-eif2 $\alpha$ ), activating transcription factor 4 (ATF4), inositolrequiring enzyme $1 \alpha$ (IRE1 $\alpha$ ) and activating transcription factor 6 (ATF6). In the first UPR branch, protein kinase RNA-like endoplasmic reticulum kinase (PERK) activation induces the phosphorylation of eif $2 \alpha$. This phosphorylation event results in the general inhibition of translation (60), while favoring the translation of the ATF4 (100). In the second UPR branch, IRE1 $\alpha$ activation triggers the splicing of X-box binding 1 (sXBP-1) mRNA. In the third UPR branch, ATF6 
activation results in its proteolytic cleavage at the Golgi apparatus, yielding a $50 \mathrm{kDa}$ ATF6 subunit (C-ATF6). There was little difference in p-eIF2 $\alpha$ or C-ATF6 in response to CSE or between Ahr/- and $A h r^{+/-}$MLFs (Fig. 6C). IRE1 $\alpha$ showed a perceptible increase in $A h r^{+/-}$MLFs exposed to CSE (Fig. 6C) without change in sXBP-1 (Fig. 6D). However, ATF4 was higher in Ahr-- MLFs (Fig. 6C). ER stress-mediated cell death is dependent on the upregulation of CHOP and growth arrest and DNA damage-inducible gene 34 (GADD34) $(46,53,77,108)$. In line with this, CHOP and GADD34 expression were both significantly higher in the CSE-treated $A h r^{-/}$MLFs compared to the CSE-treated $A h r^{+/}$MLFs (Fig. 6E and 6F). Collectively, these data support that AhR deficiency is associated with heightened ER stress.

Regulation of CHOP expression by AhR activation- We next sought to address the mechanism for the elevated CHOP expression. We first focused on mRNA expression, but there was no significant difference in Atf4 (Fig. 7A), Xbp (Fig. 7B), Chop (Fig. 7C), or Gadd34 (Fig. 7D) mRNA between the untreated or CSE-treated $A h r^{-/}$and $A h r^{+/-}$MLFs. There was also no difference in the expression of these genes in response to the AhR agonists benzo $[a]$ pyrene $(\mathrm{B}[a] \mathrm{P})$, a PAH present in cigarette smoke (39), and FICZ, an endogenous ligand (99), despite robust induction of Cyplal mRNA (Figs. S4 and S5). We conclude that these genes are not under AhR control in lung cells. Because we have previously shown that the AhR controls cyclooxygenase-2 (COX-2) protein by destabilizing the mRNA (105), we next assessed if the lower CHOP protein expression in the $\mathrm{Ahr}^{+/-}$ MLFs was a consequence of AhR-mediated Chop mRNA instability. Therefore, an Actinomycin D (ActD)-chase experiment was conducted whereby we treated cells with CSE followed by ActD for $0.5,2$ or 6 hours. ActD, at the concentrations used in this study, inhibited the induction of Cypla1 mRNA by CSE (Fig. 8A). Although there was significant Chop mRNA degradation by $6 \mathrm{~h}$ 
after ActD, there was no differences in the rate of Chop mRNA degradation observed between $A h r^{-/}$and $A h r^{+/}$MLFs (Fig. 8B). However, the attenuation of CHOP protein expression is dependent on basal AhR activation, as the selective AhR inhibitor CH-223191 (41, 105) (Fig. 8C) significantly increased CHOP mRNA and protein levels (Fig. S5, Fig. S6 and Fig. 8D). CH-223191 inhibited basal Cyplal mRNA but did not affect the other genes (e.g. Grp78, Gadd34, Atf4 or Atfo) investigated (Figs S4 and S5). Neither FICZ nor B $[a] \mathrm{P}$ affected the protein expression of CHOP (Fig. S6). Our data collectively show that AhR-deficiency results in autophagy-independent LC3II and ER stress that is characterized by ER dilation, elevated ubiquitinated proteins and increased CHOP and GADD34 protein expression. 


\section{DISCUSSION}

Although much is known about the toxicological response of the AhR to dioxin, considerably less is known about its physiological functions. Our lab has previously demonstrated that the AhR suppresses CS-induced apoptotic cell death in lung structural cells (75). Toxicant-induced cell death is mediated by a variety of inter-dependent cell death processes, including apoptosis, autophagy as well as ER stress. Herein, we show that the AhR controls LC3II in an autophagyindependent manner. Given that LC3II processing is also critical for ER stress-mediated cell death, we evaluated the contribution of the AhR towards controlling the ER stress response. Consistent with classic features of ER stress, cellular absence of the AhR was characterized by ER dilation, the accumulation of ubiquitinated proteins and an increase in the downstream UPR targets CHOP and GADD34. These features are largely consistent with two ER stress-mediated cell death mechanisms termed cytoplasmic vacuolation death and paraptosis $(40,44,88)$. These processes are also characterized by the absence of autophagosomes and elevated LC3II processing- but without changes in the expression of other autophagy-related proteins $(40,44)$, features that are also prevented by AhR expression. As a whole, we consider these to be compelling evidence that the AhR controls a novel cell death mechanism consistent with ER stress-induced cytoplasmic vacuolation death. We have however, not ruled out a role for the AhR in paraptosis. The major distinguishing feature between cytoplasmic vacuolation death and paraptosis is that paraptosis is also associated with swelling of the mitochondria (44). Although not evaluated in the present study, we have previously reported that $A h r^{-/}$MLFs exhibit a significant reduction in mitochondrial membrane potential following treatment with CSE (75). One feature of both cytoplasmic vacuolation death and paraptosis that is not consistent with absence of AhR expression is that these mechanisms do not typically present with apoptotic-like changes or caspase activation 
$(40,44)$. We have also previously reported that the CSE-treated $A h r^{-/}$MLFs exhibit morphological hallmarks of apoptosis and caspase 3 activation (75). This suggests that CSE-treated $A h r^{-/}$MLFs may be undergoing "paraptosis-like" cell death based on a phenotype that does not entirely fit all the hallmarks of either paraptosis or apoptosis. This should not be entirely surprising, however, as the AhR likely regulates multiple cell death mechanisms that could be occurring simultaneously (27). Overall, our results support that the AhR is a global regulator of cell death in lung structural cells.

The importance of homeostatic levels of AhR expression in the maintenance of lung health is underscored by the dichotomy between COPD and lung cancer. While both are diseases primarily caused by the inhalational exposure of CS, AHR overexpression is consistently observed in lung cancer $(18,48)$, while we have published that there is less AHR in COPD (79). In line with this, the AhR mediates pathogenic and pro-oncogenic effects in numerous cancer cell lines (78), while our data presented here (and that previous published) support a protective role for the AhR in attenuating pathogenic mechanisms associated with COPD development and progression $(5,24$, 79, 106). This raises the question as to how the AhR can be pathogenic in lung cancer and protective in emphysema/COPD. The answer to this question may involve homeostatic levels of AhR. COPD is largely a consequence of chronic inflammation together with reduced cell proliferation and excessive cell death, culminating in the loss of lung parenchyma. It has been previously reported that AhR-deficiency reduces cellular proliferation $(34,86)$, and our data support that AhR-deficiency exacerbates both CSE-induced lung structural cell death (75). This information collectively highlights the pathogenic nature of reduced $\mathrm{AhR}$ expression in the context of COPD. In contrast to emphysema, lung cancer is associated with increased AhR expression and is characterized by excessive cell proliferation and resistance to cell death. Moreover, AhR 
overexpression or constitutive activation in cancer cell lines induces tumor growth, whereas AhR inhibition reduces cell proliferation and migration (78). Thus, too little AhR may cause excessive cell death and the concomitant development of emphysema/COPD, whereas too much AhR may promote excessive cell proliferation, thereby contributing to the development of lung cancer. These findings collectively provide a foundation to support a the notion of a homeostatic role of the AhR in the maintenance of lung health, a notion recently proposed for the AhR in control over immune function in the gut (71).

On the more mechanistic side, it was intriguing that ULK1 expression was lower in the CSE-treated $A h r^{-/}$MLFs. ULK1 is important for the initiation of the early autophagosomal membrane (51). Therefore, we thought that ULK1 expression would be higher in the CSE-treated Ahr-- MLFs because of heightened autophagy. Recently, a noncanonical- and autophagyindependent role for ULK1 in the trafficking of proteins from the ER to the golgi has been described (38). Here, ULK1/2 was necessary for the formation of the coatomer protein complex II (COPII). This complex functions to bundle and transport newly synthesized proteins from the ER to the golgi apparatus. Thus, ULK1/2 deficiency may cause ER stress through the impairment of ER-to-golgi trafficking. Lower ULK1 in $A h r^{-/}$MLFs is therefore consistent with ER stress. It is also intriguing that $\mathrm{CHOP}$ protein expression was significantly higher after inhibition of $\mathrm{AhR}$ activation by the antagonist $\mathrm{CH}-223191$ (105). This suggests that the AhR attenuation of CHOP requires the nuclear presence of the AhR or some other form of classic AhR activity. Our data also support that basal AhR activity (i.e. in the absence of exogenous stimuli) plays an important housekeeping role in the lung by controlling cell death mechanisms. Along these lines, it is noteworthy that CSE decreased AhR protein levels in control (AhR-expressing) lung cells to a level similar to those when siRNA was used to target the AhR. Why residual AhR levels in siAhR 
cells were unaffected by CSE in not clear but could reflect the level of receptor activation. Regardless, this reduction in AhR protein levels in response to CSE is not surprising, as we have previously shown AhR protein loss in response to cigarette smoke/CSE both in vitro and in vivo $(24,55)$. Ligand-induced AhR degradation is a well-described event in AhR-mediated signaling, where there is prolonged AhR protein loss following ligand stimulation $(73,74)$. While it is thought that this down-regulation serves to terminate the ligand-induced response, it could also be that this decrease in AhR also renders cells unable to respond to endogenous ligands. This loss of AhR protein also offers an explanation to observations where there is a similar outcome with AhR deficiency as well as treatment with TCDD (43). There is also emerging evidence that the AhR plays an important physiological in part because of evidence that the AhR shuttles between the cytoplasm and nucleus even in the absence of exogenous ligand (37). In an in vitro setting this could be due to ligands present in cell culture media (66). Our findings demonstrate that there is higher LC3II along with increased markers of ER stress in Ahr-deficient cells- independent of AhR activation by exogenously-added ligands, including CSE. Moreover, inhibition of basal AhR activity with $\mathrm{CH}-223191$ also increased levels of CHOP. It is possible that AhR ligands present at low concentrations in culture media are responsible for basal AhR activation (34). Therefore, the ability of the AhR to control cell death/survival pathways is lost when AhR levels decrease/are absent or when basal AhR activity is pharmacologically-inhibited, supporting an import physiological role for the AhR in pulmonary cells.

Currently we are not sure how the AhR controls CHOP expression, as this was not associated with transcriptional control of Chop mRNA or alterations in Chop mRNA stability. Many autophagy and ER-stress related genes contain putative DREs containing the core consensus sequences of 5'-CACGCNA-3' or 3'-GTGCGNT-5' (98) but CHOP did not (Fig. S7). However,we 
speculate that the AhR regulation of $\mathrm{CHOP}$ may be occurring via a non-canonical signaling mechanism that requires AhR nuclear localization but may be independent of AhR transcriptional activities that involve the core sequence of the DRE. In line with this observation, it has been previously reported that the AhR regulation of the antioxidant sulfiredoxin1 (Srxl) (79) and the acute phase response gene serum amyloid A (SAA) (70) require AhR nuclear translocation but are independent of classic DNA-binding. A non-canonical AhR-mediated regulatory mechanism is also supported by our own data, particularly those that show elevated CHOP expression in the $A h r^{-}$ ${ }^{1}$ MLFs. It is possible that the AhR may attenuate CHOP expression via miRNA. We have shown that the AhR attenuation of CS-induced apoptosis is via its regulation of miR-196a (34). Similarly, CHOP expression can be non-canonically regulated by miR-183-5p-mediated binding to the 3 'untranslated region (UTR) of Chop mRNA (103). An alternative possibility is that elevated CHOP expression is a consequence of increased translation. GADD34 forms a complex with protein phosphatase 1c (PP1c) to dephosphorylate eif2 $\alpha$, which drives the resumption of protein synthesis (82). Consistent with this, we observed elevated GADD34 expression in the $A h r^{-/}$MLFs. Increased protein synthesis results in the production of reactive oxygen species (ROS) due to oxidative protein folding in the ER (3). The pathogenic effects of increased protein synthesis in ER stressed cells is also illustrated by the finding that inhibition of translation with cyclohexamide protects against ER stress induced cell death (40).

However, these findings do not explain why inhibition of AhR activity by CH-223191 increased CHOP protein whereas there was no significant increase in basal CHOP in $A h r^{-/-}$MLFs. This is one in a growing list of paradoxical examples as it relates to AhR effects on cellular, physiological and toxicological processes. For instance, in the four different strains of $A h^{-/}$mice that currently exist, they have different phenotypes with respect to immune function despite being 
refractory to the toxic effects of dioxin (10). Also, not all high-affinity AhR ligands cause dioxinlike toxicity (67) and different ligands can activate distinct AhR signaling pathways (68). There are also significant alterations in gene expression caused by AhR deficiency independent (and different) of/from exogenous ligand (dioxin), with over 300 genes being differentially regulated based solely on AhR expression (92). The AhR also regulates non-coding RNA, including miRNA (34). Further to this, cigarette smoke differentially regulates several miRNA in an AhR-dependent manner (76), some of which are putative targets for Chop (Ddit3) (www.Targetscan.org) and as indicated above. Thus, it could be that regulation of miRNA caused by AhR-deficiency only manifests upon cigarette smoke exposure, thereby allowing an increase in CHOP protein levels. This may be a different mechanism compared to inhibition of basal AhR activity. It is also possible that this differential regulation of CHOP (GADD153) found here is due to alterations in oxidative stress $(17,107)$. We and others have previously shown that the AhR controls oxidative stress $(54$, 79), whereby there is an increase in ROS production in $A h r^{-/}$MLFs only after CSE exposure, with little difference between $A h r^{-/}$and $A h r^{+/+}$MLFs at baseline (79). It has recently been shown that inhibition of AhR activity by CH-223191 also induces mitochondrial dysfunction and ROS formation (59). Thus, the reason we found an increase in CHOP protein in CSE-exposed $\mathrm{Ahr}^{-1-}$ MLFs as well as after inhibition of endogenous AhR activity with CH-223191 could be due to changes in the redox status of the cell. Further studies to mechanistically evaluate how the AhR controls CHOP are ongoing.

One potential complicating factor in our manuscript is the choice of cell models used to assess cell death in relation to AhR expression. For this study we utilized different cell types from both mice and humans, as well as employed different methods of AhR knock-down/knock out. We chose this approach deliberately, as this allows for a more complete picture for the role of the AhR 
in regulating cell death within the complex environment of the lung (i.e. multiple lung structural cell types). Utilizing these different models, our collective data highlight an important role for the AhR in maintaining physiological control over cell death processes involving autophagy and ER stress, regardless of the cell type or methodology employed. It was interesting to note however that using siRNA to reduce AhR protein in MLE12 cells did not impact basal LC3II levels. This was different compared to MLFs from Ahr-deficient mice as well as A549 cells whereby in the latter AhR expression was eliminated using zinc finger nuclease technology_(34). In these two AhR-deficient cells (MLFs and A549s), elimination of AhR expression resulted in an increase in basal LC3II. This suggests that some AhR expression is necessary to maintain control over LC3. It is also interesting to note that CSE increased LC3II in $A h r^{-/}$MLFs cells but not in A549-AhR ${ }^{\mathrm{KO}}$ cells. We have previously shown that reduced AhR levels in primary human lung fibroblasts as well as A549-AhR ${ }^{\mathrm{KO}}$ cells increased the basal expression of cyclooxygenase-2 (COX-2) but that there was no increase in COX-2 in CSE-exposed A549-AhR ${ }^{\mathrm{KO}}$ cells (106), despite cigarette smoke/CSE being a well-known inducer of COX-2 in many types of cells $(47,56,105)$. This likely reflects the inherent insensitivity of A549 cells to $\operatorname{CSE}(80,106)$, with higher concentrations needed to evoke a more robust response. This led us to utilize primary MLFs for the majority of our studies. Although there may be differences in cell type (epithelial versus fibroblast) or species (mouse versus human), our data highlight that the AhR controls cell survival in lung structural cells in part by regulating autophagy and ER-stress related processes.

Although we have performed select studies with individual AhR ligands present in cigarette smoke (i.e. $\mathrm{B}[a] \mathrm{P})$, we have also chosen to perform the majority of our studies using CSE, a treatment regime that has both advantages as well as limitations in evaluating the mechanistic basis of cell survival. CSE is widely-used as a model system to study in vitro effects 
of tobacco smoke $(4,5,15,34,36,104)$. Although CSE contains many components inhaled by smokers (83), this feature makes it difficult to determine which of the thousands of component(s) in cigarette smoke are mediating its toxicological effects (7). Additionally, the generation of CSE in aqueous solutions (such as cell culture media) results in the collection of the water-soluble (particulate) components of whole cigarette smoke (7). However, in vivo smoke exposure mimics many of the same features of in vitro CSE challenge $(22,69)$, making this a relevant exposure system. Another limitation is the difficulty in predicting whether the concentrations of CSE used in our studies are physiologically relevant. On the basis of nicotine levels present in CSE_(36), we speculate that exposure to the percentages of CSE used in our studies approximates what pulmonary cells might encounter in a regular smoker $(2,35)$. Thus, the use of CSE is relevant for studies designed to decipher the molecular mechanisms associated with perturbations in cell death mechanisms caused by cigarette smoking.

In conclusion, our data support that the $\mathrm{AhR}$ is a regulator of lung structural cell survival by regulating various cell death mechanisms. We report for the first time that AhR deficiency predisposes cells to ER stress and autophagy-independent LC3II. It seems that subsequent exposure of AhR-deficient cells to an environmental toxicant such as CS overwhelms the clearing capacity of the ER, which ultimately results in heightened expression of the pro-death ER stress mediator $\mathrm{CHOP}$, further accumulation of ubiquinitated protein aggregates and ultimately cell death. These findings illustrate that the AhR maintains lung health by attenuating toxicant-induced death of lung structural cells. These findings could provide the foundation for the therapeutic targeting of the AhR for the treatment of toxicant-induced lung diseases characterized by excessive cell death, such as COPD. 


\section{Figure Legends}

Fig. 1. AhR attenuates LC3II in lung structural cells. A: MLF-LC3II: There was significantly more LC3II in CSE-treated $A h r^{-/}$MLFs relative to the CSE-treated $A h r^{+/-}$MLFs. Representative western blot is shown ( $\mathrm{n}=14$ replicate experiments). $B$ : AhR siRNA-LC3: AhR knockdown in the MLE12 cells leads to higher LC3II expression following treatment with CSE. Representative western blot is shown (n=4-6). $C$ : AhR siRNA: Representative western blot of AhR knock-down in MLE12 cells. D: A549-AhR ${ }^{\mathrm{ko}}$ - LC3II: There is significantly more LC3II in the A549-AhR ${ }^{\text {ko }}$ both at baseline and upon treatment with CSE for $8 \mathrm{~h}$. Representative western blot is shown ( $\mathrm{n}=4$ replicate experiments). Results are expressed as mean \pm SEM. E: A549-AhR ${ }^{\mathrm{ko}}$-ImageStream ${ }^{\circledR}$ : A representative cellular image is shown. CSE-treated A549-AhR ${ }^{\mathrm{ko}}$ cells exhibit a markedly elevated proportion of LC3 BDI High cells relative to the CSE-treated A549 Parent cells (70.3\% and 36.2\% of population with LC3 BDI High, respectively). The y-axis is frequency (cell count) and the xaxis is cells that exhibit a BDI greater than or equal to the cut-off threshold of $\sim 3 \mathrm{e} 4$. $F$ : Mouse lung-LC3II: There is more LC3II in $A h r^{-/-}$lungs exposed to CS.

Fig. 2. Control of LC3II by the AhR requires nuclear localization and DRE binding. MLFs from $A h r^{n l s / n l s}(A)$ or $A h R^{d b d / d b d}(B)$ mice were exposed to CSE and LC3B determined by western blot. . Representative western blot is shown. Results are expressed as mean $\pm \mathrm{SEM} ; \mathrm{n}=5$ independent experiments.

Fig. 3. Increased LC3II in AhR-deficient lung structural cells is not due to impaired autophagic

flux. A: p62- MLFs: There was no difference in p62 expression between CSE-treated $A h r^{+/}$and $A h r^{-/-}$MLFs. Representative western blot of 5 independent experiments is shown. B: p62-A549- 
$\mathrm{AhR}^{\mathrm{ko}}$ : There was no difference in p62 expression between the CSE-treated A549-AhR ${ }^{\mathrm{ko}}$ and A549 Parent cells. Representative western blot of 4 independent experiments is shown. C: Flux: A549$\mathrm{AhR}^{\mathrm{ko}}$ and A549 Parent cells were treated with 2\% CSE for 8h with or without Bafilomycin A1 for an additional $2 \mathrm{~h}$. For both the A549-AhR ${ }^{\mathrm{ko}}$ and A549 Parent cells, there was a significant increase in LC3II upon the addition of Bafilomycin A1. . Western blot is representative of $n=8$ independent experiments. Results are expressed as mean \pm SEM.

Fig. 4. Increased LC3II in AhR-deficient lung structural cells is not due to increases in upstream autophagic machinery. A: ULK1 expression was higher in the CSE-treated $A h r^{+/}$MLFs relative to the CSE-treated Ahr-- MLFs (left panel), although there was no difference in ULK1 expression between the CSE-treated A549-AhR ${ }^{\mathrm{ko}}$ and A549 Parent cells (right panel). There was no significant difference in the autophagy proteins Atg5-12 (B) or Atg3 (C) in $A h r^{+/-}$and $A h r^{-/}$MLFs (left panels) or A549-AhR ${ }^{\mathrm{ko}}$ and A549 Parent cells (right panels) exposed to 2\% CSE for $8 \mathrm{~h}$. Results are expressed as mean \pm SEM of 5-10 independent experiments.

Fig 5. AhR does not alter the upregulation of genes associated with autophagy. mRNA expression of (A) Gabarapl1, (B) Beclin-1 (Becn1) and (C) Lc3b were assessed in Ahr $r^{+-}$and Ahr- MLFs (left panels) and A549-AhR ${ }^{\mathrm{ko}}$ and A549 Parent cells (right panels) following treatment with 2\% CSE for 2, 4, and 6h.. D: Cyplal mRNA: There was a significant increase in Cyplal mRNA expression in response to treatment with CSE only in $A h r^{+/}$MLFs and A549 Parent cells. Results are expressed as mean \pm SEM of $\mathrm{n}=4-7$ independent experiments.

Fig 6. AhR deficiency causes ER stress and an accumulation of ubiquitinated proteins in lung 
fibroblasts. A: TEM: Both untreated and CSE-treated $A h r^{-/}$MLFs exhibit extensively dilated ER (white arrow heads) throughout the cytoplasm (6800x magnification). $B$ : Ubiquitinated proteins were higher in the untreated and 2\% CSE-treated $A h r^{-/}$MLFs (n=4). $C$ : ER Stress Proteins: Protein expression of p-eIF2 $\alpha$, ATF4, Full (F) and cleaved (C)-ATF6 and IRE1 $\alpha$ were assessed by western blot following treatment with $2 \%$ CSE for $8 \mathrm{~h}$. Representative western blots are of at least 4 independent experiments. $D$ : Xpb-1:Xpb-1 mRNA splicing was assessed in the $A h r^{-/-}$and $A h r^{+/-}$ following treatment with $2 \% \mathrm{CSE}$ for 2, 4 and $6 \mathrm{~h}$. $X b p-1$ image is representative of 4 independent experiments. E: CHOP protein expression was significantly higher in CSE-treated $A h r^{-/}$cells. $F$ : GADD34 expression was significantly higher in both the untreated and CSE-treated $A h r^{-/}$MLFs.

Fig. 7. Elevated CHOP protein expression is not due to an upregulation of Chop mRNA. There was no change in the mRNA levels of $\operatorname{Atf} 4(A), X b p(B), C h o p(C)$ or $G A D D 34(D)$ in response to CSE. Results are expressed as mean \pm SEM of $n=9$ independent experiments.

Fig. 8. Inhibition of the AhR augments CHOP levels independent of mRNA stability, A: ActDCypla1 mRNA: Pretreatment with ActD significantly attenuated the ability of CSE to increase Cyplal mRNA in AhR-expressing MLFs ( $\mathrm{n}=3$ independent experiments). B: Chop mRNA stability- ActD Chase Experiment: $A h r^{+-}$and $A h r^{-/}$MLFs were pre-treated with 2\% CSE for $2 \mathrm{~h}$ (time 0 ) followed by treatment with $1 \mu \mathrm{g} / \mathrm{mL}$ of ActD for $0.5 \mathrm{~h}, 2 \mathrm{~h}$ and $6 \mathrm{~h} .$. Results are expressed as mean $\pm \mathrm{SEM}$ of $\mathrm{n}=4$ independent experiments. $C$ : AhR Inhibition- Cypla1 mRNA: CH-223191 inhibited basal Cypla1 mRNA expression. Results are expressed as mean \pm SEM of $n=4$ independent experiments. D: AhR Inhibition- CHOP: CH-223191 inhibited CHOP protein expression in $A h r^{+/}$MLFs. Results are expressed as mean \pm SEM of $\mathrm{n}=6$ independent experiments. 


\section{ACKNOWLEDGEMENTS}

ImageStream ${ }^{\circledR}$ data were acquired through the Immunophenotyping platform of the RI-MUHC. Processing of samples for TEM was made possible by the Facility for Electron Microscopy Research (FEMR) of McGill University. ER stress antibodies were graciously provided by Dr. Louise Larose. We would also like to acknowledge and thank Laurent Huck, Dominique Mayaki and Kwang-Bo Joung for their expertise and assistance with optimization of gene expression protocols. This work was supported by the Canada Foundation for Innovation (CFI) and the Canadian Institutes for Health Research (CIHR). C.J.B. was supported by a salary award from the Fonds de recherche du Quebec-Sante (FRQ-S). 


\section{References}

1. Ahmed S, Wang A, Celius T, and Matthews J. Zinc finger nuclease-mediated knockout of AHR or ARNT in human breast cancer cells abolishes basal and ligand-dependent regulation of CYP1B1 and differentially affects estrogen receptor alpha transactivation. Toxicol Sci 138: 89-103, 2014.

2. An Z, Wang H, Song $\mathbf{P}$, Zhang M, Geng X, and Zou MH. Nicotine-induced activation of AMP-activated protein kinase inhibits fatty acid synthase in 3T3L1 adipocytes: a role for oxidant stress. J Biol Chem 282: 26793-26801, 2007.

3. Arensdorf AM, Diedrichs D, and Rutkowski DT. Regulation of the transcriptome by ER stress: non-canonical mechanisms and physiological consequences. Front Genet 4: 256, 2013.

4. Baglole CJ, Bushinsky SM, Garcia TM, Kode A, Rahman I, Sime PJ, and Phipps

RP. Differential induction of apoptosis by cigarette smoke extract in primary human lung fibroblast strains: implications for emphysema. Am J Physiol Lung Cell Mol Physiol 291: L1929, 2006.

5. Baglole CJ, Maggirwar SB, Gasiewicz TA, Thatcher TH, Phipps RP, and Sime PJ. The aryl hydrocarbon receptor attenuates tobacco smoke-induced cyclooxygenase- 2 and prostaglandin production in lung fibroblasts through regulation of the NF-kappaB family member RelB. J Biol Chem 283: 28944-28957, 2008.

6. Baglole CJ, Reddy SY, Pollock SJ, Feldon SE, Sime PJ, Smith TJ, and Phipps RP. Isolation and phenotypic characterization of lung fibroblasts. Methods Mol Med 117: 115-127, 2005.

7. Baglole CJ, Sime PJ, and Phipps RP. Cigarette smoke-induced expression of heme oxygenase-1 in human lung fibroblasts is regulated by intracellular glutathione. Am J Physiol Lung Cell Mol Physiol 295: L624-636, 2008.

8. Bekki K, Vogel H, Li W, Ito T, Sweeney C, Haarmann-Stemmann T, Matsumura F, and Vogel CF. The aryl hydrocarbon receptor (AhR) mediates resistance to apoptosis induced in breast cancer cells. Pestic Biochem Physiol 120: 5-13, 2015.

9. Bock KW. Aryl hydrocarbon or dioxin receptor: biologic and toxic responses. Rev Physiol Biochem Pharmacol 125: 1-42, 1994.

10. Brinkmann V, Ale-Agha N, Haendeler J, and Ventura N. The Aryl Hydrocarbon Receptor (AhR) in the Aging Process: Another Puzzling Role for This Highly Conserved Transcription Factor. Front Physiol 10: 1561, 2019.

11. Bruhat A, Jousse C, Wang XZ, Ron D, Ferrara M, and Fafournoux P. Amino acid limitation induces expression of CHOP, a CCAAT/enhancer binding protein-related gene, at both transcriptional and post-transcriptional levels. J Biol Chem 272: 17588-17593, 1997.

12. Bunger MK, Glover E, Moran SM, Walisser JA, Lahvis GP, Hsu EL, and Bradfield CA. Abnormal liver development and resistance to 2,3,7,8-tetrachlorodibenzo-p-dioxin toxicity in mice carrying a mutation in the DNA-binding domain of the aryl hydrocarbon receptor.

Toxicol Sci 106: 83-92, 2008.

13. Bunger MK, Moran SM, Glover E, Thomae TL, Lahvis GP, Lin BC, and Bradfield CA. Resistance to 2,3,7,8-tetrachlorodibenzo-p-dioxin toxicity and abnormal liver development in mice carrying a mutation in the nuclear localization sequence of the aryl hydrocarbon receptor. J Biol Chem 278: 17767-17774, 2003.

14. Butler R, Inzunza J, Suzuki H, Fujii-Kuriyama Y, Warner M, and Gustafsson JA. 
Uric acid stones in the urinary bladder of aryl hydrocarbon receptor (AhR) knockout mice. Proc Natl Acad Sci U S A 109: 1122-1126, 2012.

15. Carnevali S, Petruzzelli S, Longoni B, Vanacore R, Barale R, Cipollini M, Scatena F, Paggiaro P, Celi A, and Giuntini C. Cigarette smoke extract induces oxidative stress and apoptosis in human lung fibroblasts. Am J Physiol Lung Cell Mol Physiol 284: L955-963, 2003. 16. Carp H, and Janoff A. Possible mechanisms of emphysema in smokers. In vitro suppression of serum elastase-inhibitory capacity by fresh cigarette smoke and its prevention by antioxidants. Am Rev Respir Dis 118: 617-621, 1978.

17. Carriere A, Carmona MC, Fernandez Y, Rigoulet M, Wenger RH, Penicaud L, and Casteilla L. Mitochondrial reactive oxygen species control the transcription factor CHOP10/GADD153 and adipocyte differentiation: a mechanism for hypoxia-dependent effect. $J$ Biol Chem 279: 40462-40469, 2004.

18. Chen PH, Chang H, Chang JT, and Lin P. Aryl hydrocarbon receptor in association with RelA modulates IL-6 expression in non-smoking lung cancer. Oncogene 31: 2555-2565, 2012.

19. Chen ZH, Kim HP, Sciurba FC, Lee SJ, Feghali-Bostwick C, Stolz DB, Dhir R, Landreneau RJ, Schuchert MJ, Yousem SA, Nakahira K, Pilewski JM, Lee JS, Zhang Y, Ryter SW, and Choi AM. Egr-1 regulates autophagy in cigarette smoke-induced chronic obstructive pulmonary disease. PLoS One 3: e3316, 2008.

20. Chen ZH, Lam HC, Jin Y, Kim HP, Cao J, Lee SJ, Ifedigbo E, Parameswaran H, Ryter SW, and Choi AM. Autophagy protein microtubule-associated protein 1 light chain-3B (LC3B) activates extrinsic apoptosis during cigarette smoke-induced emphysema. Proc Natl Acad Sci US A 107: 18880-18885, 2010.

21. Council NR. Review of the Department of Defence Enhanced Particulate Matter Surveillance Program Report. edited by Defence Do. Washington: The National Academies Press, 2010, p. 85.

22. Csiszar A, Labinskyy N, Podlutsky A, Kaminski PM, Wolin MS, Zhang C, Mukhopadhyay P, Pacher P, Hu F, de Cabo R, Ballabh P, and Ungvari Z. Vasoprotective effects of resveratrol and SIRT1: attenuation of cigarette smoke-induced oxidative stress and proinflammatory phenotypic alterations. Am J Physiol Heart Circ Physiol 294: H2721-2735, 2008.

23. de la Calle C, Joubert PE, Law HK, Hasan M, and Albert ML. Simultaneous assessment of autophagy and apoptosis using multispectral imaging cytometry. Autophagy 7 : 1045-1051, 2011.

24. de Souza AR, Zago M, Eidelman DH, Hamid Q, and Baglole CJ. Aryl hydrocarbon receptor $(\mathrm{AhR})$ attenuation of subchronic cigarette smoke-induced pulmonary neutrophilia is associated with retention of nuclear RelB and suppression of intercellular adhesion molecule-1 (ICAM-1). Toxicol Sci 140: 204-223, 2014.

25. Esser C, and Rannug A. The aryl hydrocarbon receptor in barrier organ physiology, immunology, and toxicology. Pharmacol Rev 67: 259-279, 2015.

26. Fernandez-Salguero PM, Hilbert DM, Rudikoff S, Ward JM, and Gonzalez FJ. Aryl-hydrocarbon receptor-deficient mice are resistant to 2,3,7,8-tetrachlorodibenzo-p-dioxininduced toxicity. Toxicol Appl Pharmacol 140: 173-179, 1996.

27. Fink SL, and Cookson BT. Apoptosis, pyroptosis, and necrosis: mechanistic description of dead and dying eukaryotic cells. Infect Immun 73: 1907-1916, 2005.

28. Galluzzi L, Vicencio JM, Kepp O, Tasdemir E, Maiuri MC, and Kroemer G. To die 
or not to die: that is the autophagic question. Curr Mol Med 8: 78-91, 2008.

29. Ghio AJ. Particle exposures and infections. Infection 42: 459-467, 2014.

30. Guo H, Lin W, Zhang X, Zhang X, Hu Z, Li L, Duan Z, Zhang J, and Ren F.

Kaempferol induces hepatocellular carcinoma cell death via endoplasmic reticulum stressCHOP-autophagy signaling pathway. Oncotarget 8: 82207-82216, 2017.

31. Harstad EB, Guite CA, Thomae TL, and Bradfield CA. Liver deformation in Ahr-null mice: evidence for aberrant hepatic perfusion in early development. Mol Pharmacol 69: 15341541, 2006.

32. Hassler JR, Scheuner DL, Wang S, Han J, Kodali VK, Li P, Nguyen J, George JS, Davis C, Wu SP, Bai Y, Sartor M, Cavalcoli J, Malhi H, Baudouin G, Zhang Y, Yates JR, III, Itkin-Ansari P, Volkmann N, and Kaufman RJ. The IRE1alpha/XBP1s Pathway Is Essential for the Glucose Response and Protection of beta Cells. PLoS Biol 13: e1002277, 2015. 33. Hecht E, Zago M, Sarill M, Rico de Souza A, Gomez A, Matthews J, Hamid Q, Eidelman DH, and Baglole CJ. Aryl hydrocarbon receptor-dependent regulation of miR-196a expression controls lung fibroblast apoptosis but not proliferation. Toxicol Appl Pharmacol 2014.

34. Hecht E, Zago M, Sarill M, Rico de Souza A, Gomez A, Matthews J, Hamid Q, Eidelman DH, and Baglole CJ. Aryl hydrocarbon receptor-dependent regulation of miR-196a expression controls lung fibroblast apoptosis but not proliferation. Toxicol Appl Pharmacol 280: 511-525, 2014.

35. Holden WE, Maier JM, and Malinow MR. Cigarette smoke extract increases albumin flux across pulmonary endothelium in vitro. J Appl Physiol (1985) 66: 443-449, 1989.

36. Hoshino Y, Mio T, Nagai S, Miki H, Ito I, and Izumi T. Cytotoxic effects of cigarette smoke extract on an alveolar type II cell-derived cell line. Am J Physiol Lung Cell Mol Physiol 281: L509-516, 2001.

37. Ikuta T, Kobayashi Y, and Kawajiri K. Cell density regulates intracellular localization of aryl hydrocarbon receptor. J Biol Chem 279: 19209-19216, 2004.

38. Joo JH, Wang B, Frankel E, Ge L, Xu L, Iyengar R, Li-Harms X, Wright C, Shaw TI, Lindsten T, Green DR, Peng J, Hendershot LM, Kilic F, Sze JY, Audhya A, and Kundu M. The Noncanonical Role of ULK/ATG1 in ER-to-Golgi Trafficking Is Essential for Cellular Homeostasis. Mol Cell 62: 982, 2016.

39. Kaiserman MJ, and Rickert WS. Carcinogens in tobacco smoke: benzo[a]pyrene from Canadian cigarettes and cigarette tobacco. Am J Public Health 82: 1023-1026, 1992.

40. Kar R, Singha PK, Venkatachalam MA, and Saikumar P. A novel role for MAP1 LC3 in nonautophagic cytoplasmic vacuolation death of cancer cells. Oncogene 28: 2556-2568, 2009.

41. Kim SH, Henry EC, Kim DK, Kim YH, Shin KJ, Han MS, Lee TG, Kang JK, Gasiewicz TA, Ryu SH, and Suh PG. Novel compound 2-methyl-2H-pyrazole-3-carboxylic acid (2-methyl-4-o-tolylazo-phenyl)-amide (CH-223191) prevents 2,3,7,8-TCDD-induced toxicity by antagonizing the aryl hydrocarbon receptor. Mol Pharmacol 69: 1871-1878, 2006.

42. Kovacs AL, and Klionsky DJ. A pioneer in the field of autophagy microscopy: Attila L Kovacs. Autophagy 9: 1908-1921, 2013.

43. Latchney SE, Hein AM, O'Banion MK, DiCicco-Bloom E, and Opanashuk LA. Deletion or activation of the aryl hydrocarbon receptor alters adult hippocampal neurogenesis and contextual fear memory. J Neurochem 125: 430-445, 2013.

44. Lee WJ, Chien MH, Chow JM, Chang JL, Wen YC, Lin YW, Cheng CW, Lai GM, 
Hsiao M, and Lee LM. Nonautophagic cytoplasmic vacuolation death induction in human PC$3 \mathrm{M}$ prostate cancer by curcumin through reactive oxygen species -mediated endoplasmic reticulum stress. Sci Rep 5: 10420, 2015.

45. Lee YK, and Lee JA. Role of the mammalian ATG8/LC3 family in autophagy: differential and compensatory roles in the spatiotemporal regulation of autophagy. BMB Rep 49: 424-430, 2016.

46. Lei Y, Wang S, Ren B, Wang J, Chen J, Lu J, Zhan S, Fu Y, Huang L, and Tan J. CHOP favors endoplasmic reticulum stress-induced apoptosis in hepatocellular carcinoma cells via inhibition of autophagy. PLoS One 12: e0183680, 2017.

47. Lim HJ, Park JH, Jo C, Yoon K, and Koh YH. Cigarette smoke extracts and cadmium induce COX-2 expression through gamma-secretase-mediated p38 MAPK activation in C6 astroglia cells. PLoS One 14: e0212749, 2019.

48. Lin P, Chang H, Tsai WT, Wu MH, Liao YS, Chen JT, and Su JM. Overexpression of aryl hydrocarbon receptor in human lung carcinomas. Toxicol Pathol 31: 22-30, 2003.

49. Lippai M, and Low P. The role of the selective adaptor p62 and ubiquitin-like proteins in autophagy. Biomed Res Int 2014: 832704, 2014.

50. Liu K, Shi Y, Guo X, Wang S, Ouyang Y, Hao M, Liu D, Qiao L, Li N, Zheng J, and Chen D. CHOP mediates ASPP2-induced autophagic apoptosis in hepatoma cells by releasing Beclin-1 from Bcl-2 and inducing nuclear translocation of Bcl-2. Cell Death Dis 5: e1323, 2014. 51. Mack HI, Zheng B, Asara JM, and Thomas SM. AMPK-dependent phosphorylation of ULK1 regulates ATG9 localization. Autophagy 8: 1197-1214, 2012.

52. Majumder M, Huang C, Snider MD, Komar AA, Tanaka J, Kaufman RJ, Krokowski D, and Hatzoglou M. A novel feedback loop regulates the response to endoplasmic reticulum stress via the cooperation of cytoplasmic splicing and mRNA translation. Mol Cell Biol 32: 992-1003, 2012.

53. Marciniak SJ, Yun CY, Oyadomari S, Novoa I, Zhang Y, Jungreis R, Nagata K, Harding HP, and Ron D. CHOP induces death by promoting protein synthesis and oxidation in the stressed endoplasmic reticulum. Genes Dev 18: 3066-3077, 2004.

54. Marlowe JL, Fan Y, Chang X, Peng L, Knudsen ES, Xia Y, and Puga A. The aryl hydrocarbon receptor binds to E2F1 and inhibits E2F1-induced apoptosis. Mol Biol Cell 19: 3263-3271, 2008.

55. Martey CA, Baglole CJ, Gasiewicz TA, Sime PJ, and Phipps RP. The aryl hydrocarbon receptor is a regulator of cigarette smoke induction of the cyclooxygenase and prostaglandin pathways in human lung fibroblasts. Am J Physiol Lung Cell Mol Physiol 289: L391-399, 2005.

56. Martey CA, Pollock SJ, Turner CK, O'Reilly KM, Baglole CJ, Phipps RP, and Sime PJ. Cigarette smoke induces cyclooxygenase-2 and microsomal prostaglandin E2 synthase in human lung fibroblasts: implications for lung inflammation and cancer. Am J Physiol Lung Cell Mol Physiol 287: L981-991, 2004.

57. Mimura J, Yamashita K, Nakamura K, Morita M, Takagi TN, Nakao K, Ema M, Sogawa K, Yasuda M, Katsuki M, and Fujii-Kuriyama Y. Loss of teratogenic response to 2,3,7,8-tetrachlorodibenzo-p-dioxin (TCDD) in mice lacking the Ah (dioxin) receptor. Genes Cells 2: 645-654, 1997.

58. Mofarrahi M, Guo Y, Haspel JA, Choi AM, Davis EC, Gouspillou G, Hepple RT, Godin R, Burelle Y, and Hussain SN. Autophagic flux and oxidative capacity of skeletal muscles during acute starvation. Autophagy 9: 1604-1620, 2013. 
59. Mohammadi-Bardbori A, Omidi M, and Arabnezhad MR. Impact of CH223191Induced Mitochondrial Dysfunction on Its Aryl Hydrocarbon Receptor Agonistic and Antagonistic Activities. Chem Res Toxicol 32: 691-697, 2019.

60. Mokas S, Mills JR, Garreau C, Fournier MJ, Robert F, Arya P, Kaufman RJ, Pelletier J, and Mazroui R. Uncoupling stress granule assembly and translation initiation inhibition. Mol Biol Cell 20: 2673-2683, 2009.

61. Monick MM, Powers LS, Walters K, Lovan N, Zhang M, Gerke A, Hansdottir S, and Hunninghake GW. Identification of an autophagy defect in smokers' alveolar macrophages. J Immunol 185: 5425-5435, 2010.

62. Morales-Hernandez A, Gonzalez-Rico FJ, Roman AC, Rico-Leo E, AlvarezBarrientos A, Sanchez L, Macia A, Heras SR, Garcia-Perez JL, Merino JM, and Fernandez-Salguero PM. Alu retrotransposons promote differentiation of human carcinoma cells through the aryl hydrocarbon receptor. Nucleic Acids Res 44: 4665-4683, 2016.

63. Nakatogawa H. Two ubiquitin-like conjugation systems that mediate membrane formation during autophagy. Essays Biochem 55: 39-50, 2013.

64. Nebert DW. Aryl hydrocarbon receptor (AHR): "pioneer member" of the basichelix/loop/helix per-Arnt-sim (bHLH/PAS) family of "sensors" of foreign and endogenous signals. Prog Lipid Res 67: 38-57, 2017.

65. Nemmar A, Holme JA, Rosas I, Schwarze PE, and Alfaro-Moreno E. Recent advances in particulate matter and nanoparticle toxicology: a review of the in vivo and in vitro studies. Biomed Res Int 2013: 279371, 2013.

66. Oberg M, Bergander L, Hakansson H, Rannug U, and Rannug A. Identification of the tryptophan photoproduct 6-formylindolo[3,2-b]carbazole, in cell culture medium, as a factor that controls the background aryl hydrocarbon receptor activity. Toxicol Sci 85: 935-943, 2005.

67. Okey AB. An aryl hydrocarbon receptor odyssey to the shores of toxicology: the Deichmann Lecture, International Congress of Toxicology-XI. Toxicol Sci 98: 5-38, 2007.

68. Okino ST, Pookot D, Basak S, and Dahiya R. Toxic and chemopreventive ligands preferentially activate distinct aryl hydrocarbon receptor pathways: implications for cancer prevention. Cancer Prev Res (Phila) 2: 251-256, 2009.

69. Orosz Z, Csiszar A, Labinskyy N, Smith K, Kaminski PM, Ferdinandy P, Wolin MS, Rivera A, and Ungvari Z . Cigarette smoke-induced proinflammatory alterations in the endothelial phenotype: role of NAD(P)H oxidase activation. Am J Physiol Heart Circ Physiol 292: H130-139, 2007.

70. Patel RD, Murray IA, Flaveny CA, Kusnadi A, and Perdew GH. Ah receptor represses acute-phase response gene expression without binding to its cognate response element. Lab Invest 89: 695-707, 2009.

71. Pernomian L, Duarte-Silva M, and de Barros Cardoso CR. The Aryl Hydrocarbon Receptor (AHR) as a Potential Target for the Control of Intestinal Inflammation: Insights from an Immune and Bacteria Sensor Receptor. Clin Rev Allergy Immunol 2020.

72. Petrulis JR, and Perdew GH. The role of chaperone proteins in the aryl hydrocarbon receptor core complex. Chem Biol Interact 141: 25-40, 2002.

73. Pollenz RS. Specific blockage of ligand-induced degradation of the Ah receptor by proteasome but not calpain inhibitors in cell culture lines from different species. Biochem Pharmacol 74: 131-143, 2007.

74. Prokipcak RD, and Okey AB. Downregulation of the Ah receptor in mouse hepatoma cells treated in culture with 2,3,7,8-tetrachlorodibenzo-p-dioxin. Can J Physiol Pharmacol 69: 
1204-1210, 1991.

75. Rico de Souza A, Zago M, Pollock SJ, Sime PJ, Phipps RP, and Baglole CJ. Genetic Ablation of the Aryl Hydrocarbon Receptor Causes Cigarette Smoke-induced Mitochondrial Dysfunction and Apoptosis. J Biol Chem 286: 43214-43228, 2011.

76. Rogers S, de Souza AR, Zago M, Iu M, Guerrina N, Gomez A, Matthews J, and Baglole CJ. Aryl hydrocarbon receptor (AhR)-dependent regulation of pulmonary miRNA by chronic cigarette smoke exposure. Sci Rep 7: 40539, 2017.

77. Rutkowski DT, Arnold SM, Miller CN, Wu J, Li J, Gunnison KM, Mori K, Sadighi Akha AA, Raden D, and Kaufman RJ. Adaptation to ER stress is mediated by differential stabilities of pro-survival and pro-apoptotic mRNAs and proteins. PLoS Biol 4: e374, 2006.

78. Safe S, Lee SO, and Jin UH. Role of the aryl hydrocarbon receptor in carcinogenesis and potential as a drug target. Toxicol Sci 135: 1-16, 2013.

79. Sarill M, Zago M, Sheridan JA, Nair P, Matthews J, Gomez A, Roussel L, Rousseau S, Hamid Q, Eidelman DH, and Baglole CJ. The aryl hydrocarbon receptor suppresses cigarette-smoke-induced oxidative stress in association with dioxin response element (DRE)independent regulation of sulfiredoxin 1. Free Radic Biol Med 89: 342-357, 2015.

80. Scheffler S, Dieken H, Krischenowski O, and Aufderheide M. Cytotoxic Evaluation of e-Liquid Aerosol using Different Lung-Derived Cell Models. Int J Environ Res Public Health 12: 12466-12474, 2015.

81. Schmidt JV, Su GH, Reddy JK, Simon MC, and Bradfield CA. Characterization of a murine Ahr null allele: involvement of the Ah receptor in hepatic growth and development. Proc Natl Acad Sci U S A 93: 6731-6736, 1996.

82. Schonthal AH. Endoplasmic reticulum stress: its role in disease and novel prospects for therapy. Scientifica (Cairo) 2012: 857516, 2012.

83. Shapiro SD. Smoke gets in your cells. Am J Respir Cell Mol Biol 31: 481-482, 2004.

84. Shimba S, Komiyama K, Moro I, and Tezuka M. Overexpression of the aryl

hydrocarbon receptor (AhR) accelerates the cell proliferation of A549 cells. J Biochem 132: 795 802, 2002.

85. Shimizu Y, Nakatsuru Y, Ichinose M, Takahashi Y, Kume H, Mimura J, FujiiKuriyama Y, and Ishikawa T. Benzo[a]pyrene carcinogenicity is lost in mice lacking the aryl hydrocarbon receptor. Proc Natl Acad Sci U S A 97: 779-782, 2000.

86. Shivanna B, Maity S, Zhang S, Patel A, Jiang W, Wang L, Welty SE, Belmont J, Coarfa C, and Moorthy B. Gene Expression Profiling Identifies Cell Proliferation and Inflammation as the Predominant Pathways Regulated by Aryl Hydrocarbon Receptor in Primary Human Fetal Lung Cells Exposed to Hyperoxia. Toxicol Sci 152: 155-168, 2016.

87. Singh KP, Garrett RW, Casado FL, and Gasiewicz TA. Aryl hydrocarbon receptornull allele mice have hematopoietic stem/progenitor cells with abnormal characteristics and functions. Stem Cells Dev 20: 769-784, 2011.

88. Sperandio S, de Belle I, and Bredesen DE. An alternative, nonapoptotic form of programmed cell death. Proc Natl Acad Sci U S A 97: 14376-14381, 2000.

89. Tagawa Y, Hiramatsu N, Kasai A, Hayakawa K, Okamura M, Yao J, and Kitamura M. Induction of apoptosis by cigarette smoke via ROS-dependent endoplasmic reticulum stress and CCAAT/enhancer-binding protein-homologous protein (CHOP). Free Radic Biol Med 45: 50-59, 2008.

90. Tanos R, Patel RD, Murray IA, Smith PB, Patterson AD, and Perdew GH. Aryl hydrocarbon receptor regulates the cholesterol biosynthetic pathway in a dioxin response 
element-independent manner. Hepatology 55: 1994-2004, 2012.

91. Thatcher TH, Maggirwar SB, Baglole CJ, Lakatos HF, Gasiewicz TA, Phipps RP, and Sime PJ. Aryl hydrocarbon receptor-deficient mice develop heightened inflammatory responses to cigarette smoke and endotoxin associated with rapid loss of the nuclear factorkappaB component RelB. Am J Pathol 170: 855-864, 2007.

92. Tijet N, Boutros PC, Moffat ID, Okey AB, Tuomisto J, and Pohjanvirta R. Aryl hydrocarbon receptor regulates distinct dioxin-dependent and dioxin-independent gene batteries. Mol Pharmacol 69: 140-153, 2006.

93. Tomkiewicz C, Herry L, Bui LC, Metayer C, Bourdeloux M, Barouki R, and Coumoul X. The aryl hydrocarbon receptor regulates focal adhesion sites through a nongenomic FAK/Src pathway. Oncogene 32: 1811-1820, 2013.

94. Valavanidis A, Fiotakis K, and Vlachogianni T. Airborne particulate matter and human health: toxicological assessment and importance of size and composition of particles for oxidative damage and carcinogenic mechanisms. J Environ Sci Health C Environ Carcinog Ecotoxicol Rev 26: 339-362, 2008.

95. van den Bogaard EH, Bergboer JG, Vonk-Bergers M, van Vlijmen-Willems IM, Hato SV, van der Valk PG, Schroder JM, Joosten I, Zeeuwen PL, and Schalkwijk J. Coal tar induces AHR-dependent skin barrier repair in atopic dermatitis. J Clin Invest 123: 917-927, 2013.

96. Villa M, Gialitakis M, Tolaini M, Ahlfors H, Henderson CJ, Wolf CR, Brink R, and Stockinger B. Aryl hydrocarbon receptor is required for optimal B-cell proliferation. EMBO J 36: 116-128, 2017.

97. Wang WB, Feng LX, Yue QX, Wu WY, Guan SH, Jiang BH, Yang M, Liu X, and Guo DA. Paraptosis accompanied by autophagy and apoptosis was induced by celastrol, a natural compound with influence on proteasome, ER stress and Hsp90. J Cell Physiol 227: 21962206, 2012.

98. Watson AJ, Weir-Brown KI, Bannister RM, Chu FF, Reisz-Porszasz S, FujiiKuriyama Y, Sogawa K, and Hankinson O. Mechanism of action of a repressor of dioxindependent induction of Cypla1 gene transcription. Mol Cell Biol 12: 2115-2123, 1992.

99. Wei YD, Helleberg H, Rannug U, and Rannug A. Rapid and transient induction of CYP1A1 gene expression in human cells by the tryptophan photoproduct 6-formylindolo[3,2b]carbazole. Chem Biol Interact 110: 39-55, 1998.

100. Wek RC, and Cavener DR. Translational control and the unfolded protein response. Antioxid Redox Signal 9: 2357-2371, 2007.

101. Wikenheiser KA, Vorbroker DK, Rice WR, Clark JC, Bachurski CJ, Oie HK, and Whitsett JA. Production of immortalized distal respiratory epithelial cell lines from surfactant protein C/simian virus 40 large tumor antigen transgenic mice. Proc Natl Acad Sci US A 90: 11029-11033, 1993.

102. Yamamoto A, Tagawa Y, Yoshimori T, Moriyama Y, Masaki R, and Tashiro Y. Bafilomycin A1 prevents maturation of autophagic vacuoles by inhibiting fusion between autophagosomes and lysosomes in rat hepatoma cell line, H-4-II-E cells. Cell Struct Funct 23: 33-42, 1998.

103. Yao Y, Lu Q, Hu Z, Yu Y, Chen Q, and Wang QK. A non-canonical pathway regulates ER stress signaling and blocks ER stress-induced apoptosis and heart failure. Nat Commun 8: 133, 2017.

104. Zago M, Rico de Souza A, Hecht E, Rousseau S, Hamid Q, Eidelman DH, and 
Baglole CJ. The NF-kappaB family member RelB regulates microRNA miR-146a to suppress cigarette smoke-induced COX-2 protein expression in lung fibroblasts. Toxicol Lett 226: 107116, 2014.

105. Zago M, Sheridan JA, Nair P, Rico de Souza A, Gallouzi IE, Rousseau S, Di Marco S, Hamid Q, Eidelman DH, and Baglole CJ. Aryl Hydrocarbon Receptor-Dependent Retention of Nuclear HuR Suppresses Cigarette Smoke-Induced Cyclooxygenase-2 Expression Independent of DNA-Binding. PLoS One 8: e74953, 2013.

106. Zago M, Sheridan JA, Traboulsi H, Hecht E, Zhang Y, Guerrina N, Matthews J, Nair P, Eidelman DH, Hamid Q, and Baglole CJ. Low levels of the AhR in chronic obstructive pulmonary disease (COPD)-derived lung cells increases COX-2 protein by altering mRNA stability. PLoS One 12: e0180881, 2017.

107. Zhang Z, Yang XY, and Cohen DM. Urea-associated oxidative stress and Gadd153/CHOP induction. Am J Physiol 276: F786-793, 1999.

108. Zinszner H, Kuroda M, Wang X, Batchvarova N, Lightfoot RT, Remotti H, Stevens JL, and Ron D. CHOP is implicated in programmed cell death in response to impaired function of the endoplasmic reticulum. Genes Dev 12: 982-995, 1998. 


\section{Figure 1}

A. MLF- LC3II

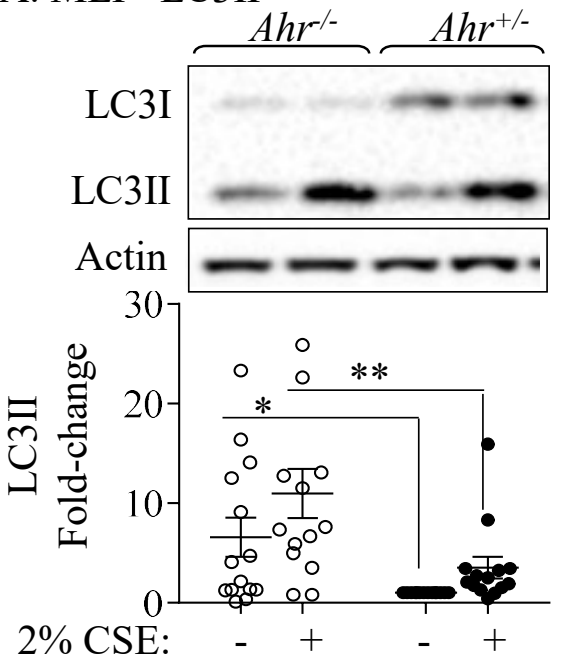

B. AhR siRNA-LC3

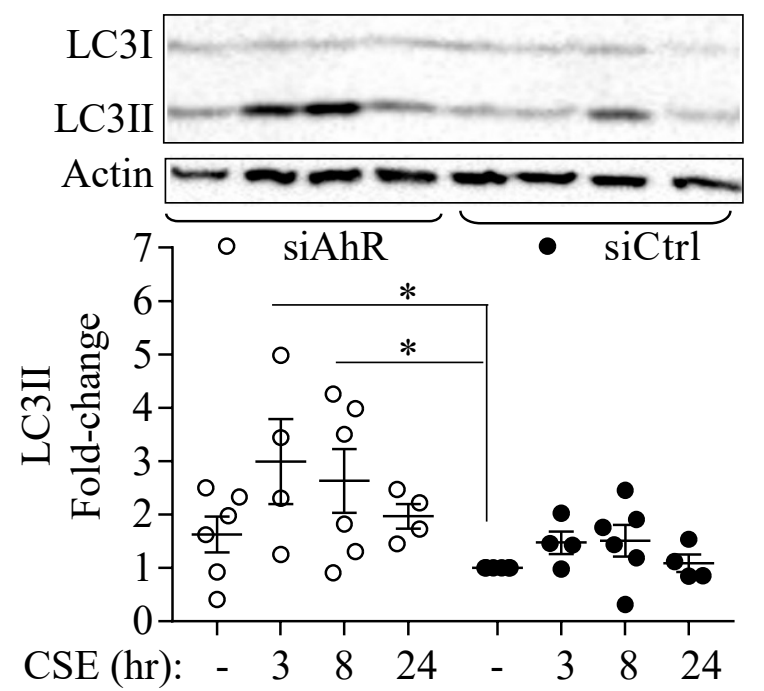

C. AhR siRNA

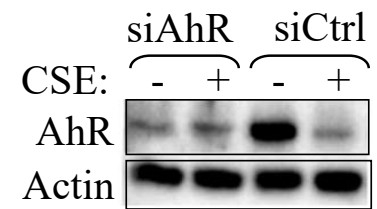

\section{A549-AhR ko- LC3II}

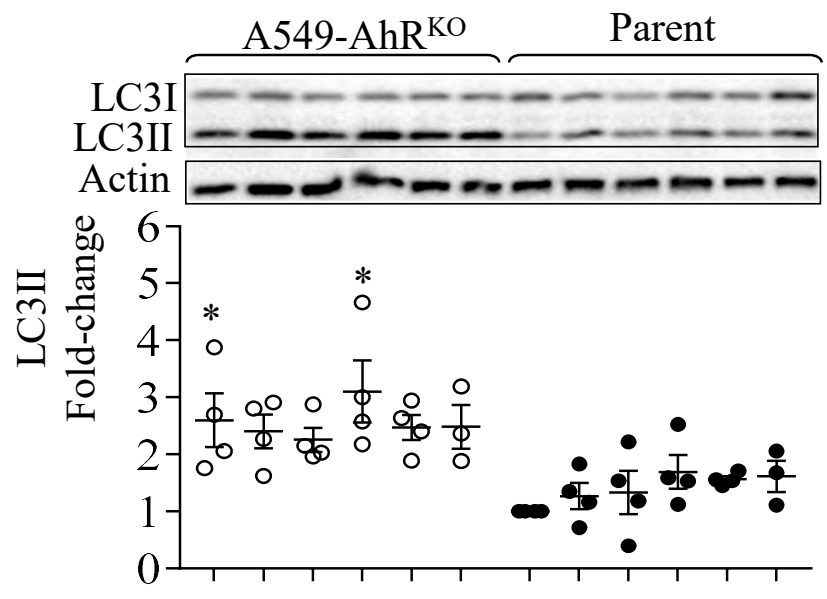

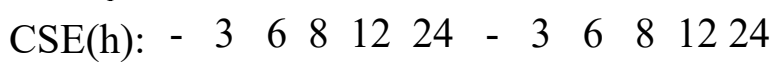

E. A549-AhR ${ }^{\text {ko }}$ - ImageStream ${ }^{\circledR}$

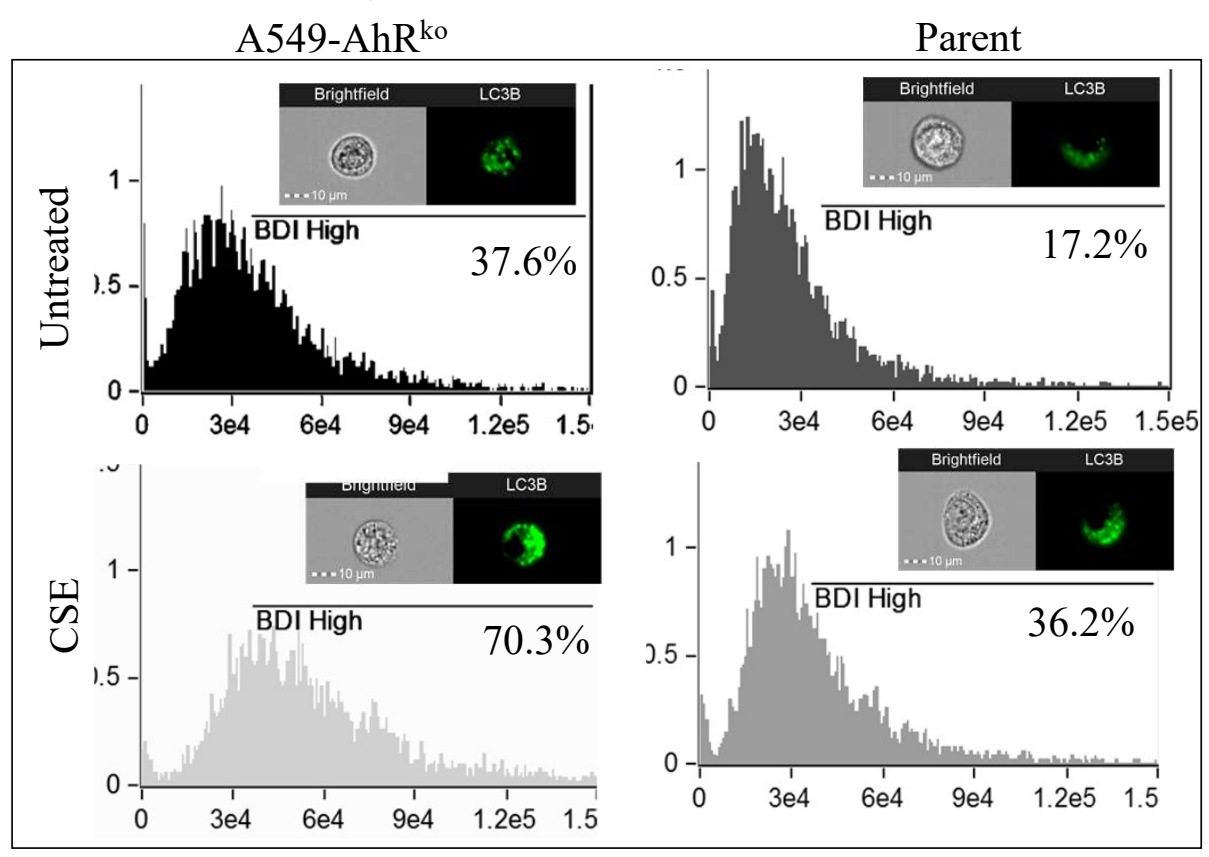

F. Mouse lung- LC3II

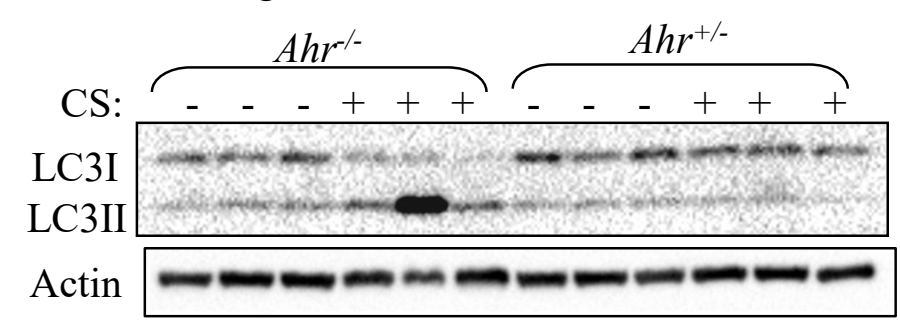

G. Mouse lung- LC3II Densitometry

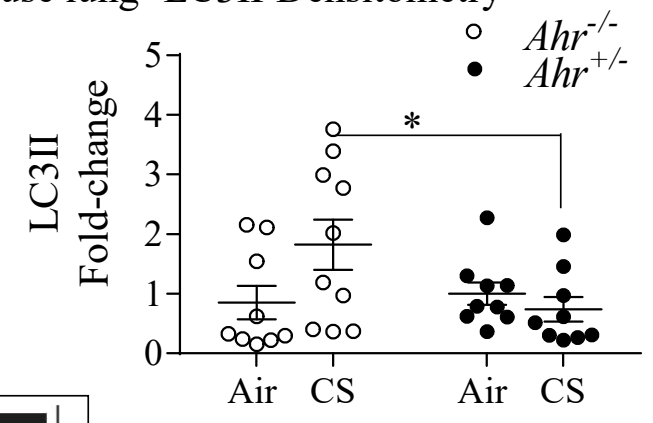


Figure 2

A. $A h r^{n l s / n l s} \mathrm{MLF}$

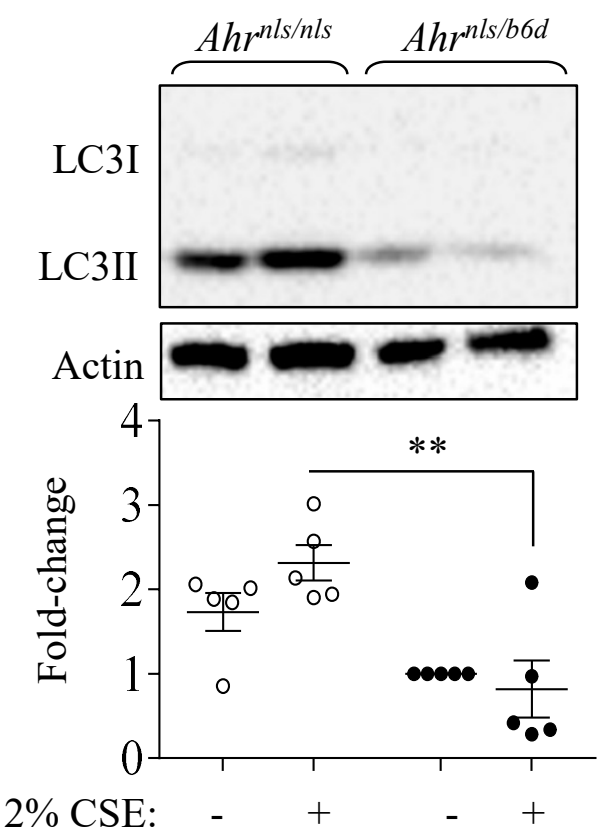

B. $A h r^{d b d / d b d}$ MLF

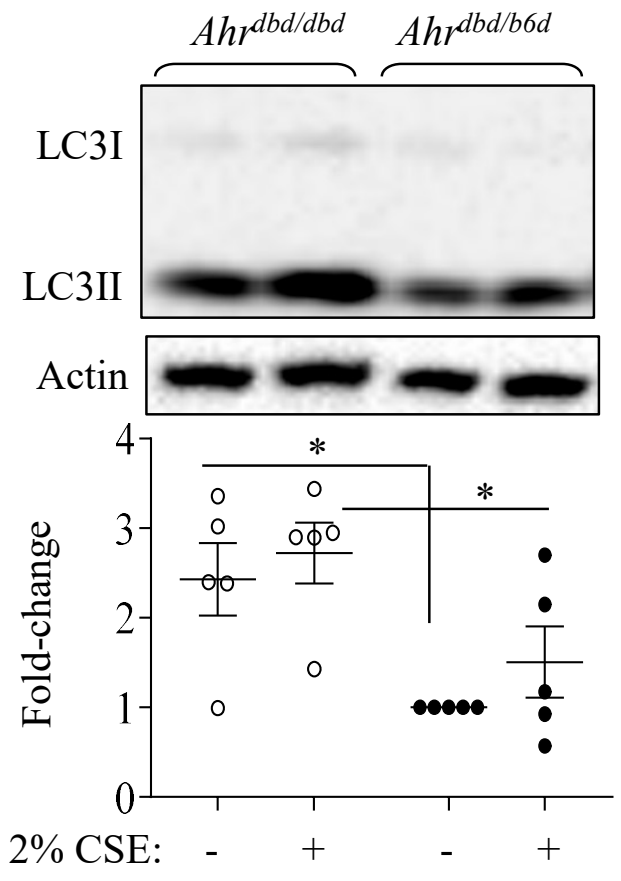


Figure 3
A. p62-MLFs
B. p62-A549-AhR ko
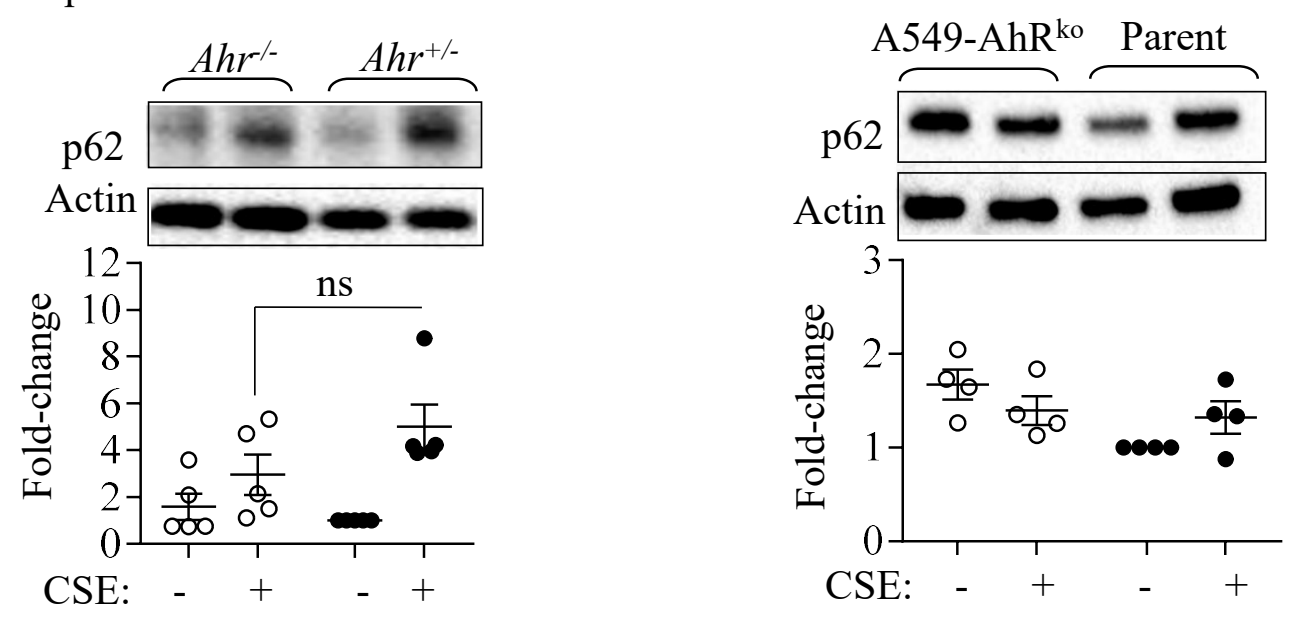

C. Flux
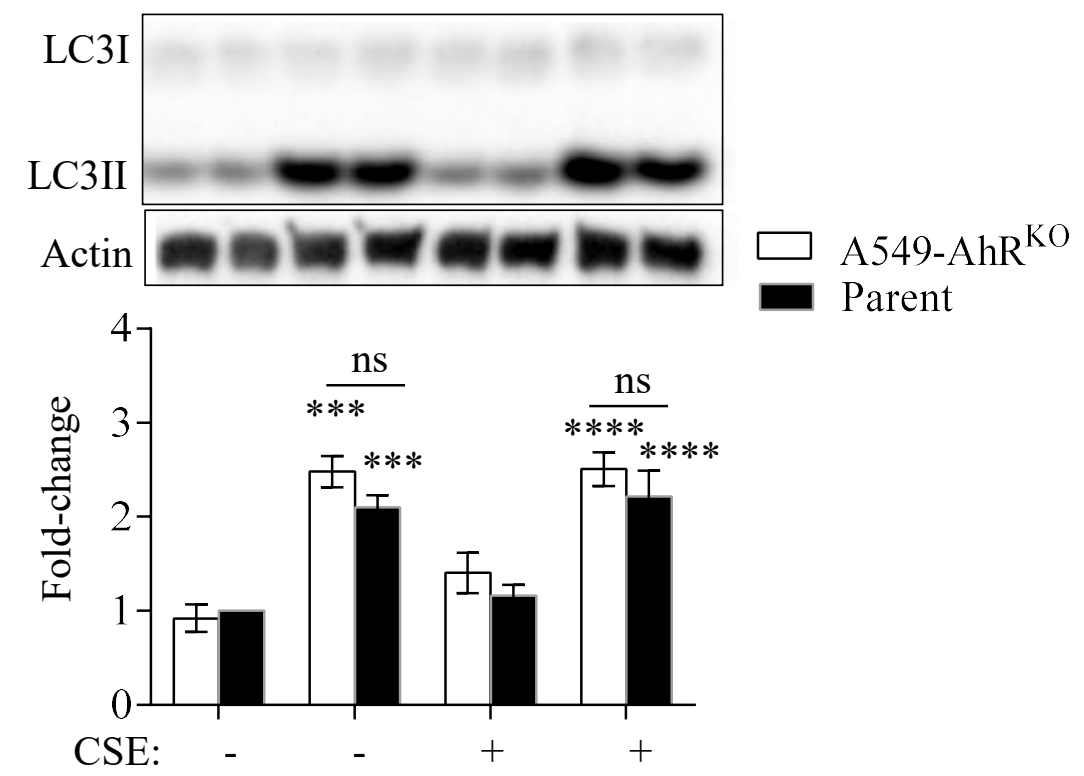

Bafilomycin A1: $\quad-\quad+\quad+\quad-\quad+$ 
Figure 4

A. ULK1
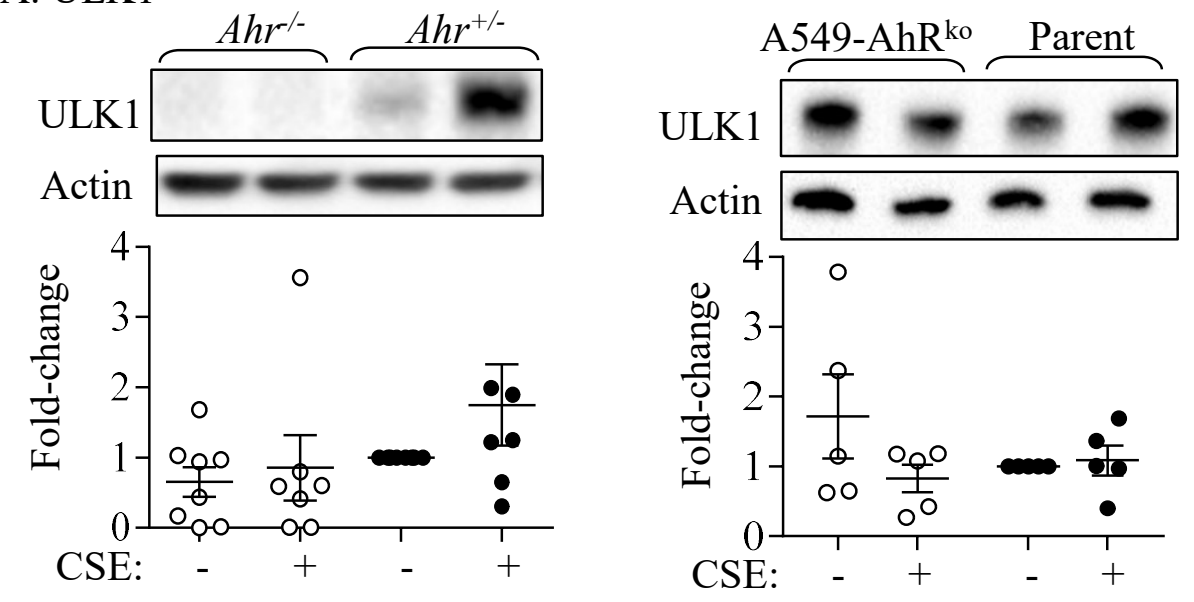

B. Atg5-12
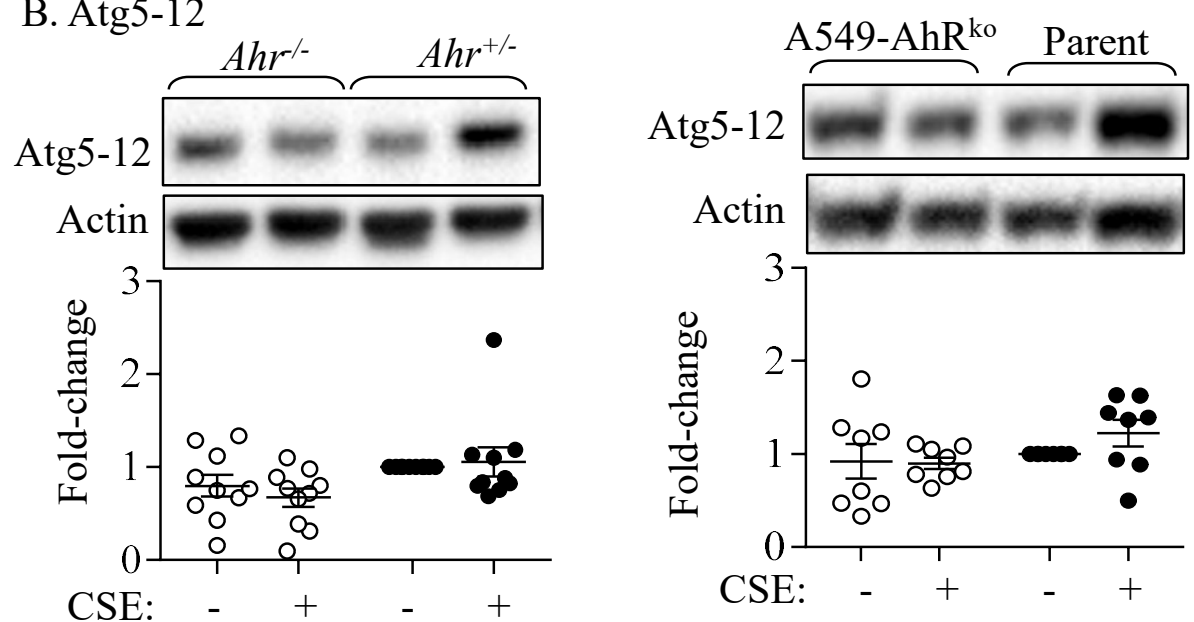

C. Atg3
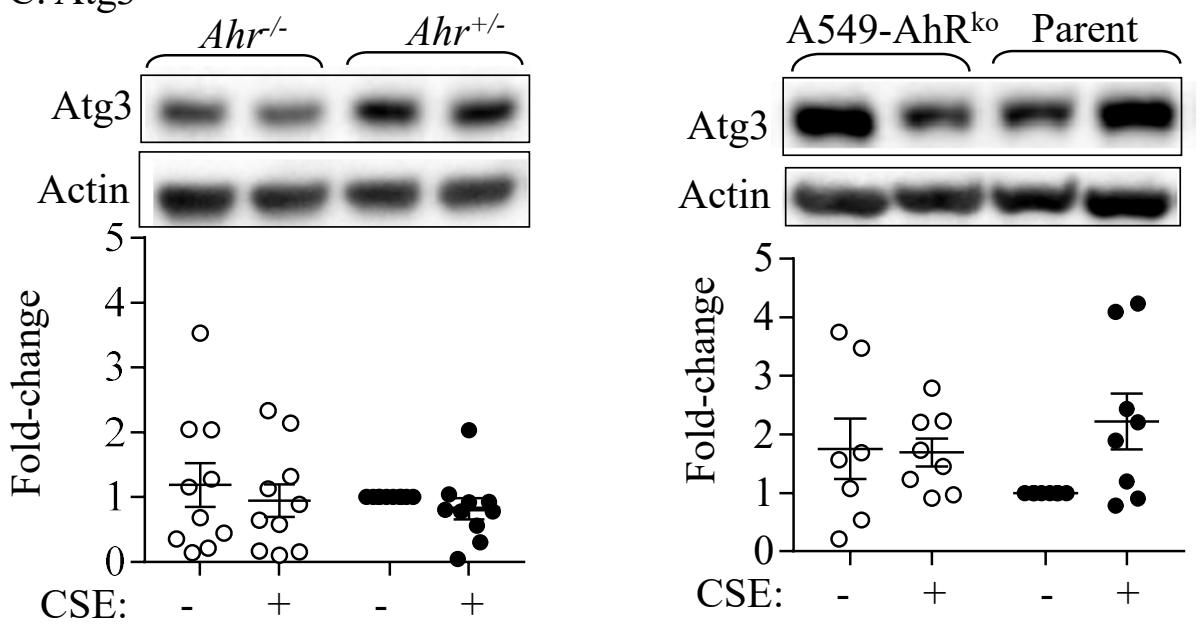
Figure 5

A. Gabarapll mRNA
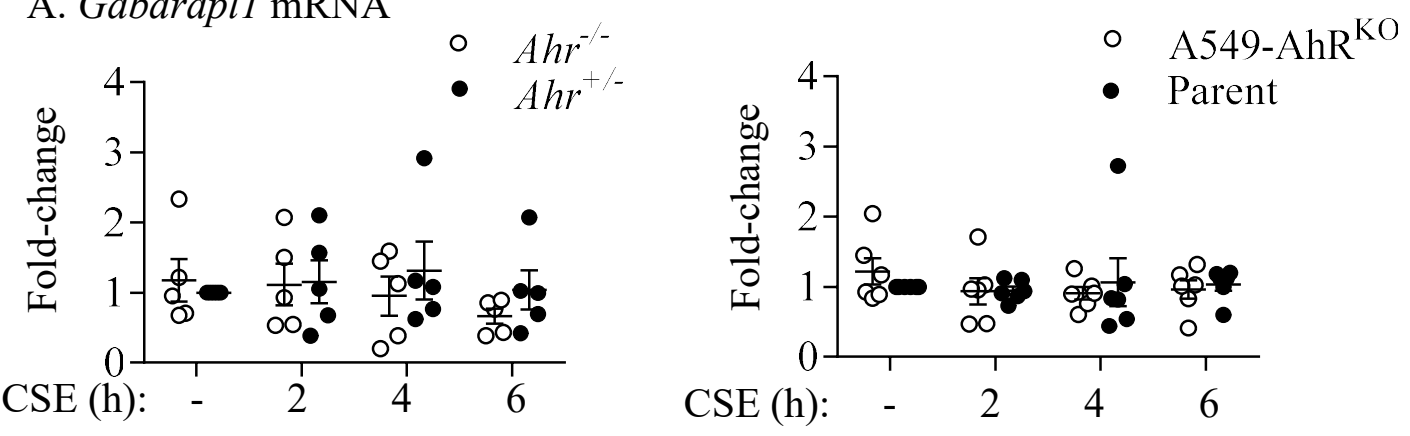

B. Becn 1 mRNA
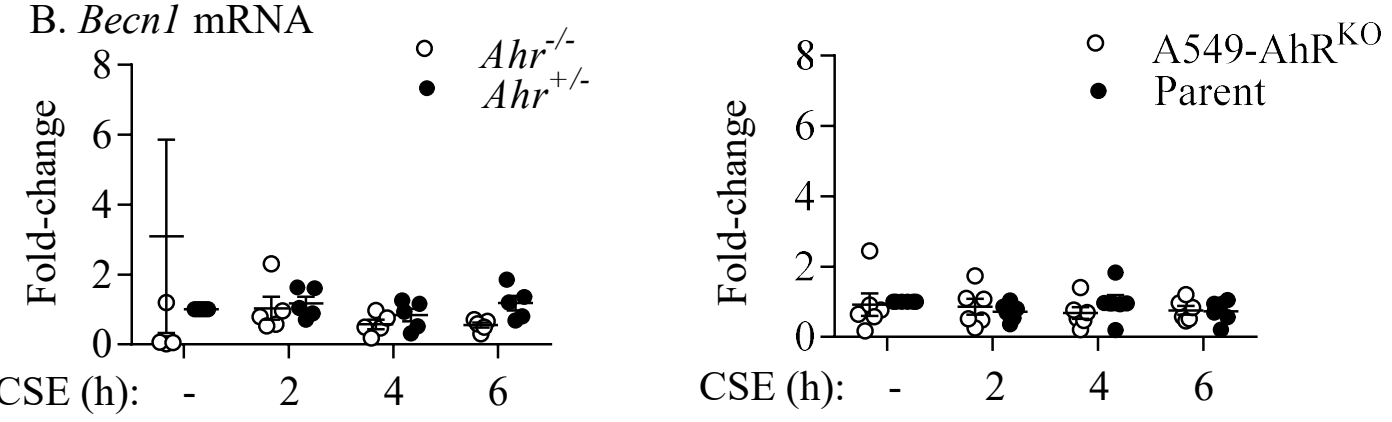

C. $L c 3 b$ mRNA
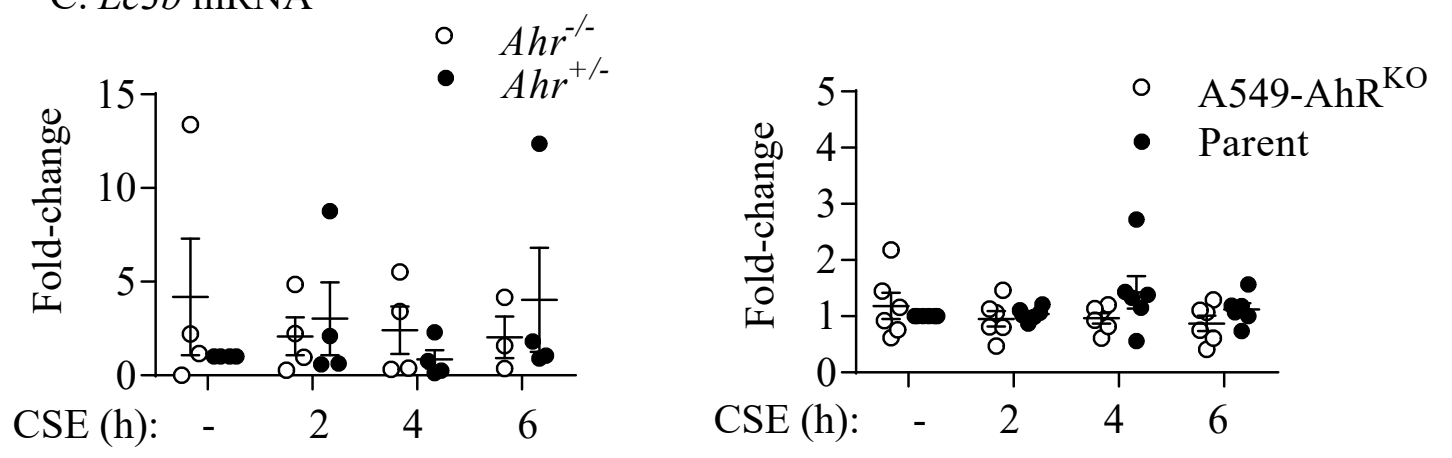

D. Cyplal mRNA
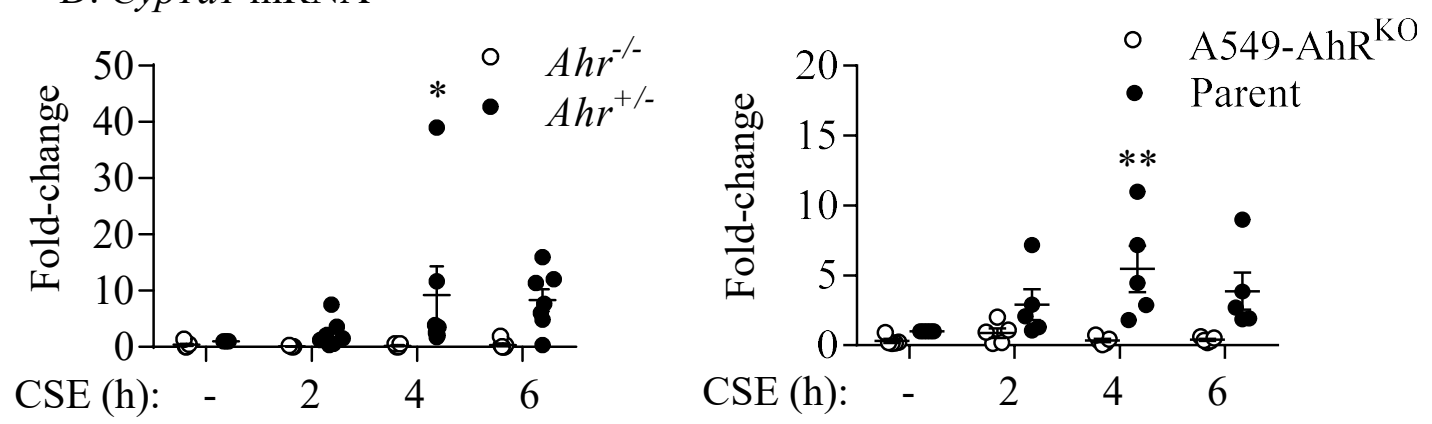
Figure 6

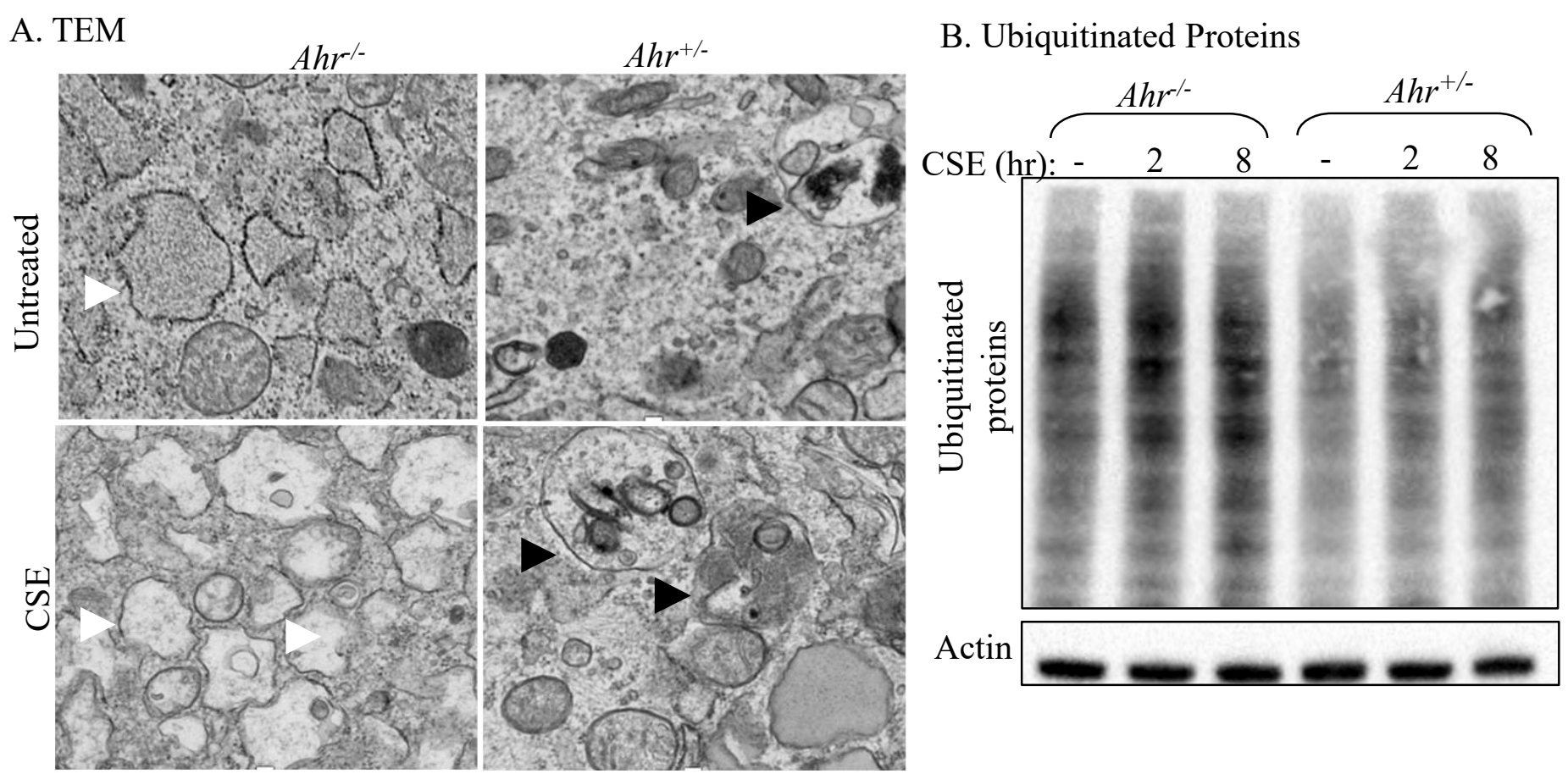

C. ER Stress Proteins

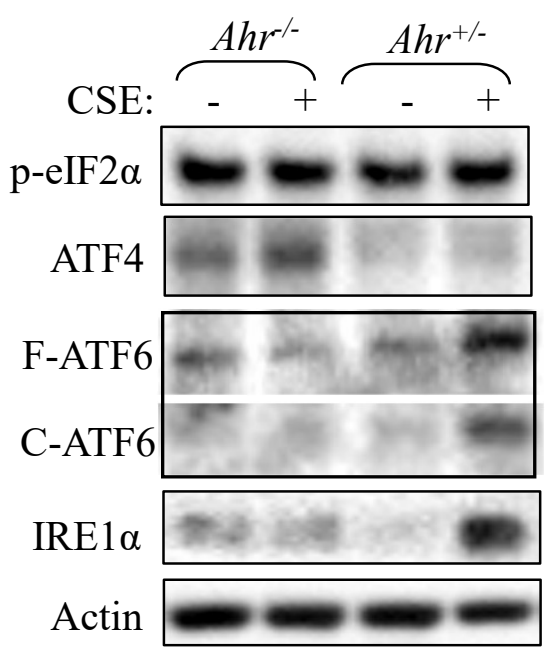

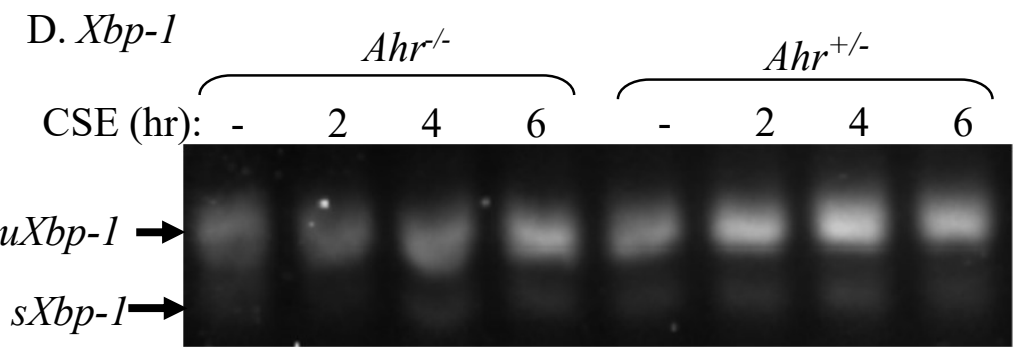
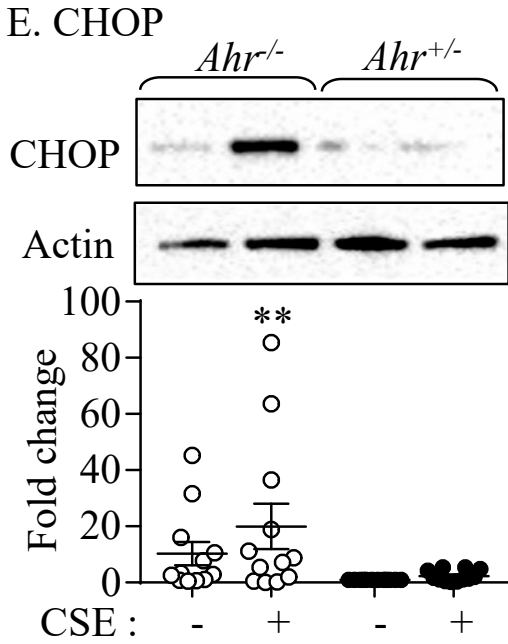

F. GADD34
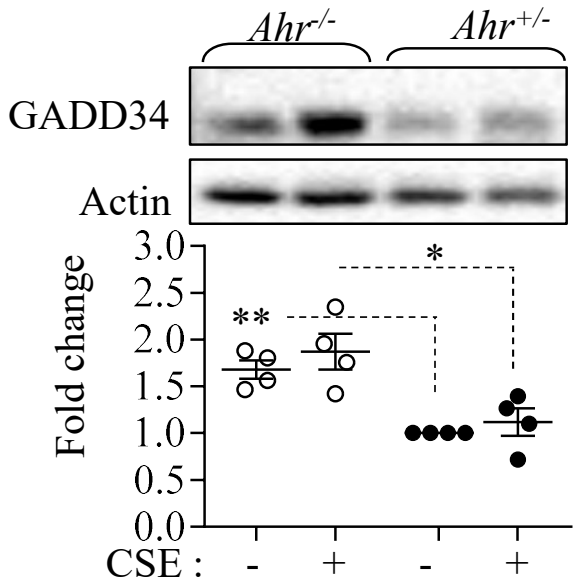
Figure 7
A. Atf 4 mRNA
B. $X b p$ mRNA
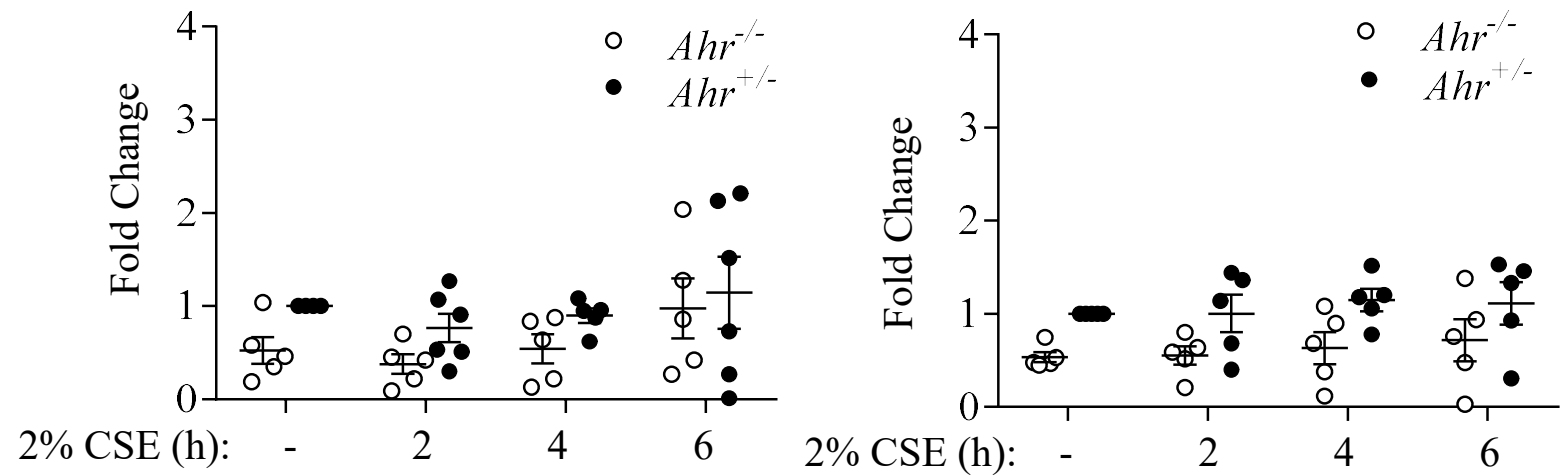

C. Chop mRNA

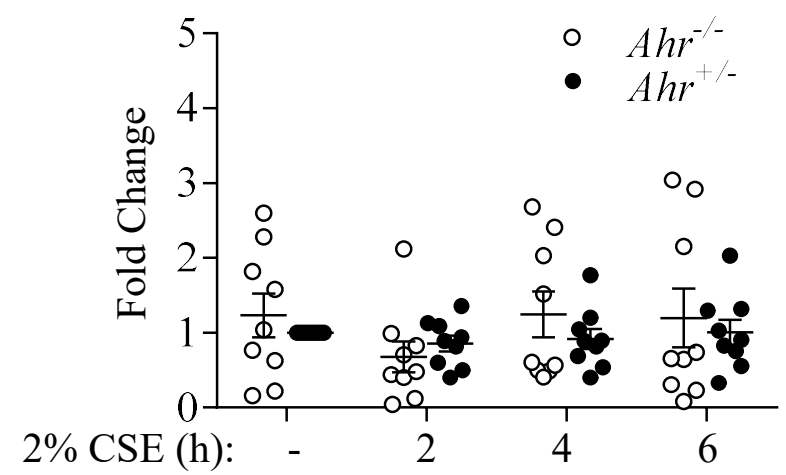

D. Gadd34 mRNA

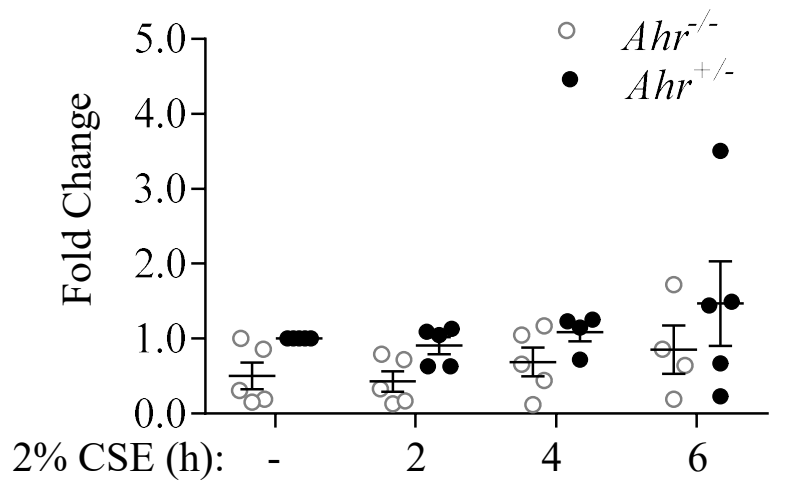




\section{Figure 8}

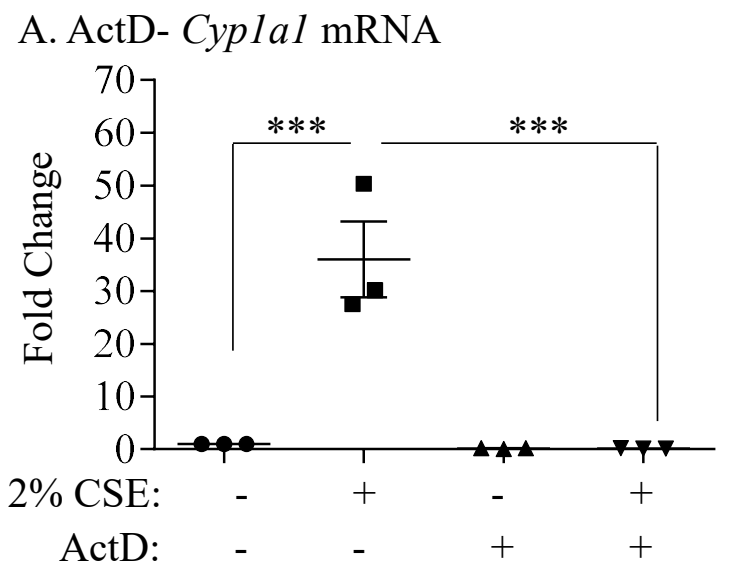

B. Chop mRNA-ActD Chase Experiment
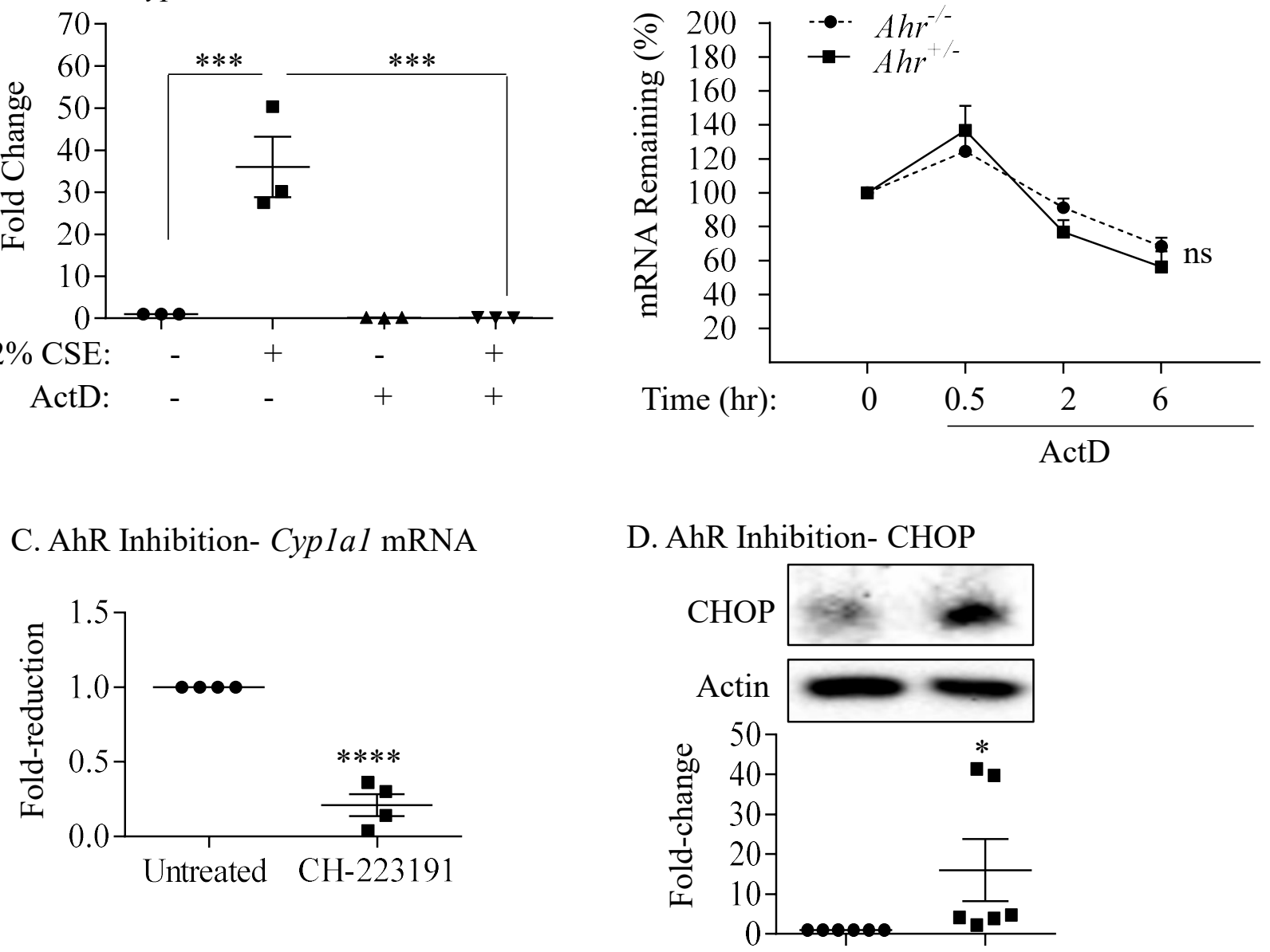

CH-223191: - $\quad+$ 


\section{Online Supplement}

The aryl hydrocarbon receptor $(\mathrm{AhR})$ reduces $\mathrm{LC} 3 \mathrm{~B}$ processing by controlling endoplasmic reticulum (ER) stress

Necola Guerrina, Noof Aloufi, Fangyi Shi, Kashmira Prasade, Caitlin Mehrotra, Hussein

Traboulsi, Jason Matthews, David H. Eidelman, Qutayba Hamid and Carolyn J. Baglole 


\section{Figure Legends}

Figure S1. AhR protein expression. Whole cell lysates from mouse lung fibroblasts cultured under standard culture conditions and western blot analysis performed for verification of AhR protein levels.

Figure S2. Full length blots of antibodies used for quantification. Representative, full-length blot are shown. The approximate molecular weight is indicated.

Figure S3. Transmission electron micrograph (TEM) images of CSE-exposed control and Ahr-deficient MLFs. Whole TEM images of cells in the presence of absence of CSE. The white box indicated the portion of the cell that was digitally enlarged and presented in Figure 6A.

Figure S4. Effect of AhR ligands on gene expression- 2 hrs. AhR-expressing MLFs were treated with $2 \% \mathrm{CSE}, 1 \mu \mathrm{M} \mathrm{B}[a] \mathrm{P}, 5 \mathrm{nM}$ FICZ or $10 \mu \mathrm{M} \mathrm{CH}-223191$ for 2 hours and qRT-PCR performed for CyplA1 (A), Grp787 (B) GADD34 (C) Atf4 (D), Atf6 (E) and Chop (F) mRNA expression. Results are expressed as the mean \pm SEM of 4 independent experiments.

Figure S5. Effect of AhR ligands on gene expression- 6 hrs. AhR-expressing MLFs were treated with $2 \% \mathrm{CSE}, 1 \mu \mathrm{M} \mathrm{B}[a] \mathrm{P}, 5 \mathrm{nM}$ FICZ or $10 \mu \mathrm{M} \mathrm{CH}-223191$ for 6 hours and qRT-PCR performed for CyplA1 (A), Grp787 (B) GADD34 (C) Atf4 (D), Atf6 (E) and Chop (F) mRNA expression. Results are expressed as the mean \pm SEM of 4 independent experiments.

Figure S6. AhR agonists have no effect on CHOP protein expression. AhR-expressing MLFs were treated with $2 \% \mathrm{CSE}, 1 \mu \mathrm{M} \mathrm{B}[a] \mathrm{P}, 5 \mathrm{nM} \mathrm{FICZ}$ or $10 \mu \mathrm{M} \mathrm{CH}-223191$ for 8 or 24 hours and western blot analysis performed for CHOP expression. Representative western blot shown of 3 independent experiments.

Figure S7. Putative dioxin responsive element (DREs) in key autophagy and ER-stress related genes. The sequence of potential DREs (5'-TNGCGTG-3') and (5'-CACGCNA-3') sites in the promoter region (up to $-5 \mathrm{~kb}$ ) of mouse Becnl, human Becnl and human LC3 are shown. The promoter of CYP1A1 is presented as the classical AhR target gene containing several known DRE. 
Figure S1

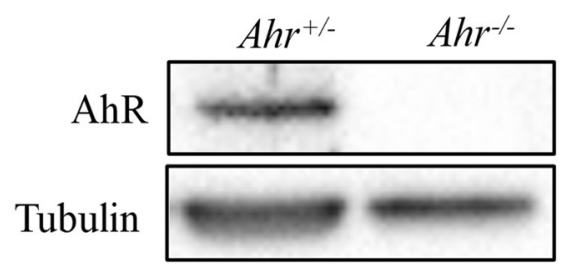


Figure S2
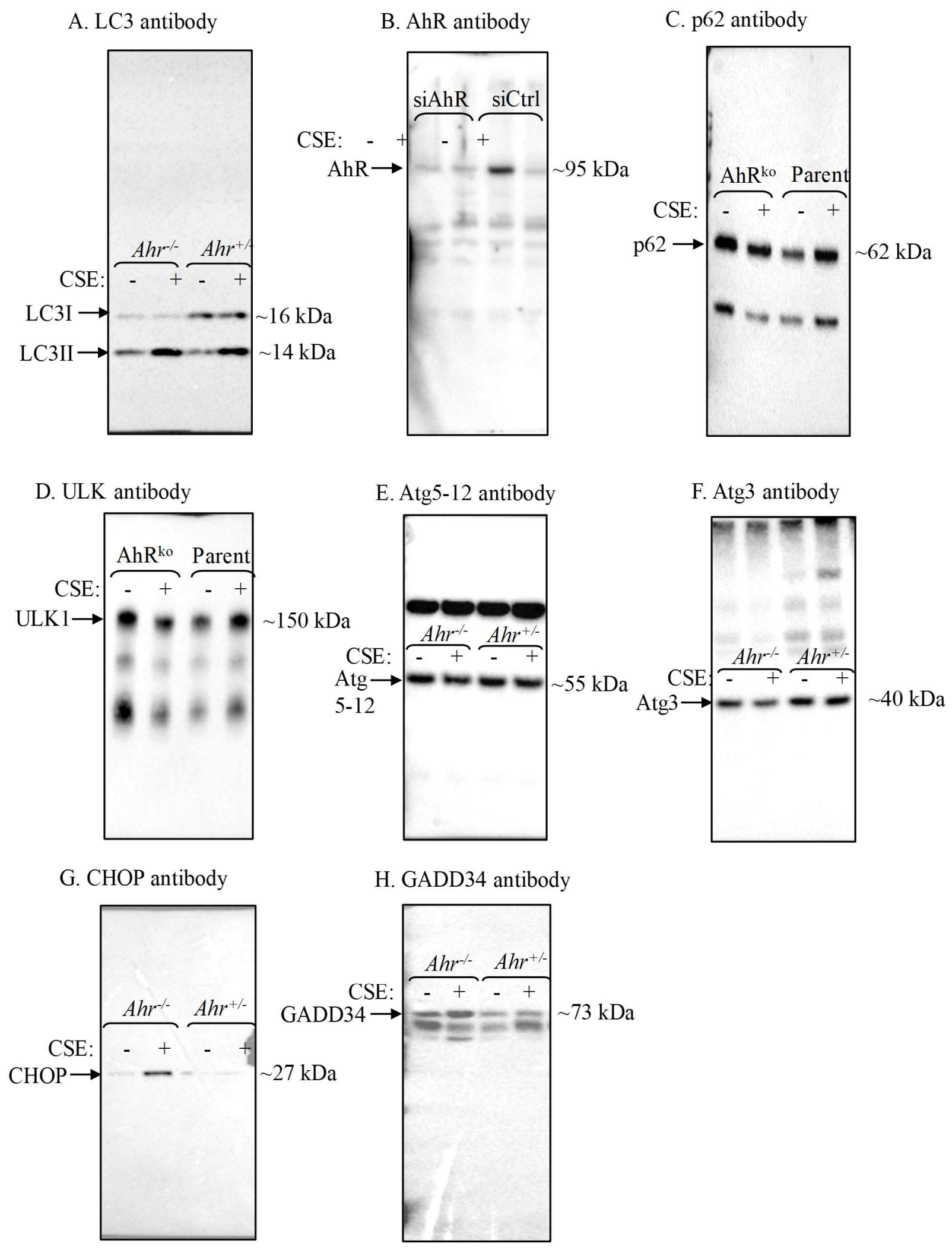


\section{Figure S3}
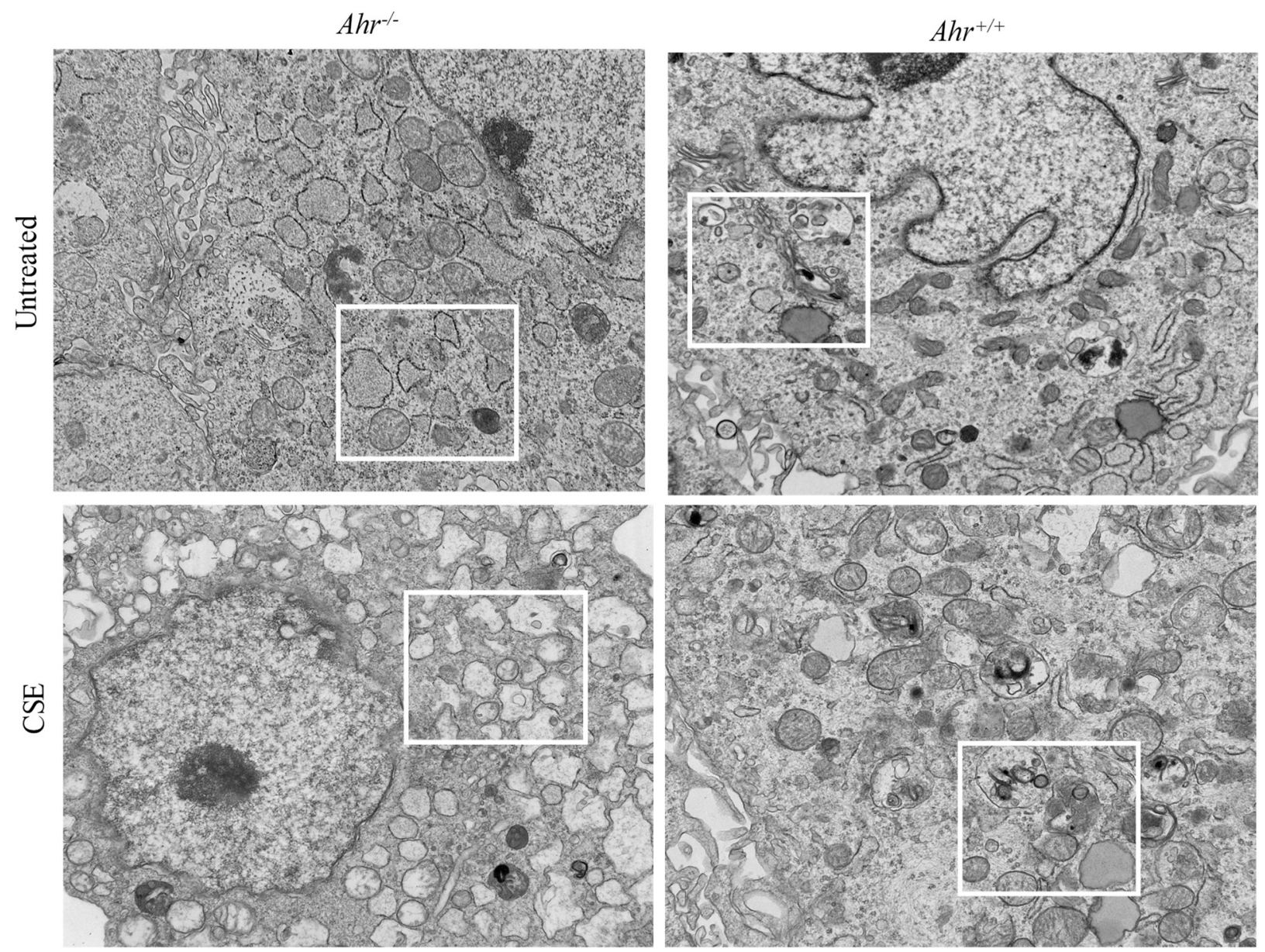
Figure S4

\section{A. Cyp1a1 mRNA- $2 \mathrm{hr}$}

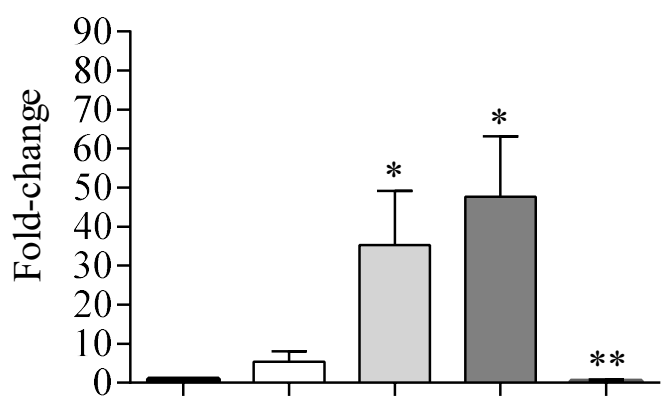

2\% CSE:

$\mathrm{B}[\mathrm{a}] \mathrm{P}: \quad-\quad-\quad+\quad-$

FICZ: - $\quad-\quad-\quad \begin{array}{llll}- & - & + & -\end{array}$

\section{CH-223191:}

C. GADD34 mRNA- $2 \mathrm{hr}$

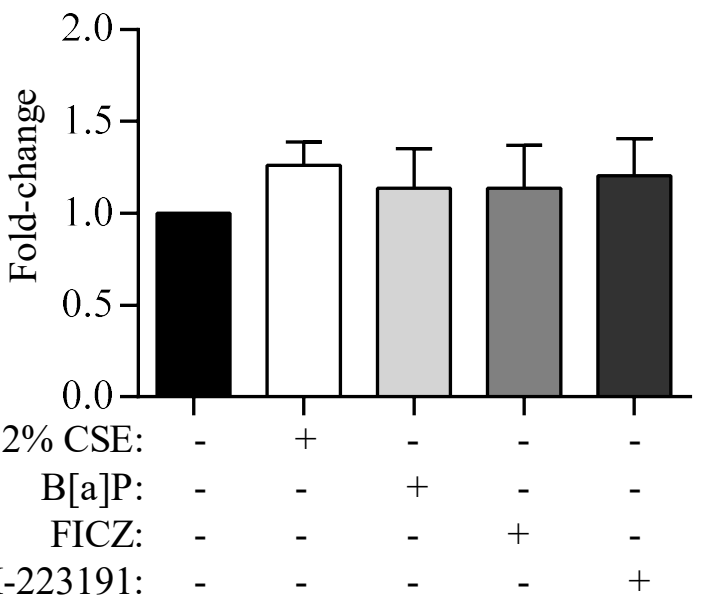

CH-223191:

E. Atf6 mRNA- $2 \mathrm{hr}$

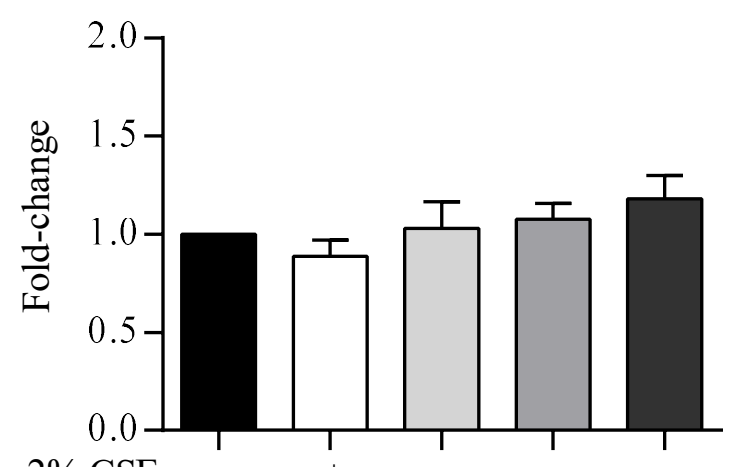

2\% CSE:

$\mathrm{B}[\mathrm{a}] \mathrm{P}:$

FICZ:

CH-223191:
B. Grp78 mRNA- $2 \mathrm{hr}$

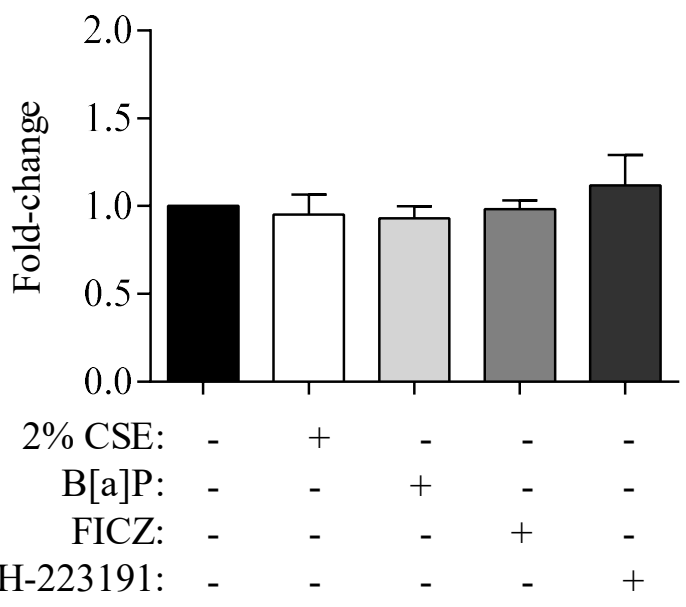

D. Atf4 mRNA- $2 \mathrm{hr}$

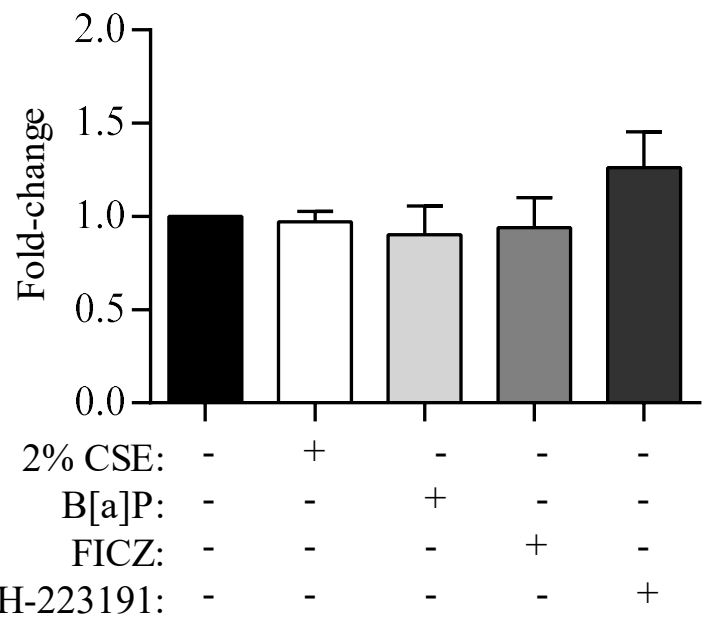

F. Chop mRNA- $2 \mathrm{hr}$

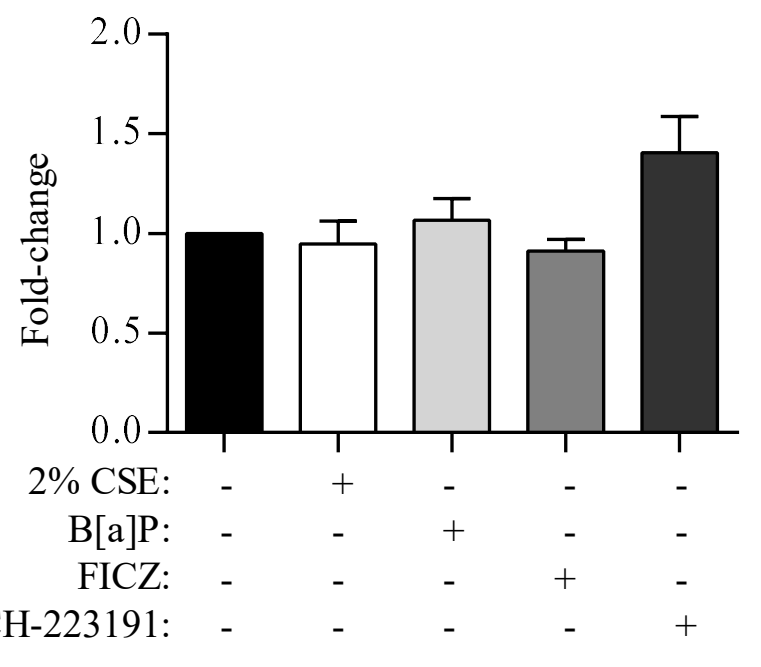


Figure S5

A. Cyp1a1 mRNA- $6 \mathrm{hr}$

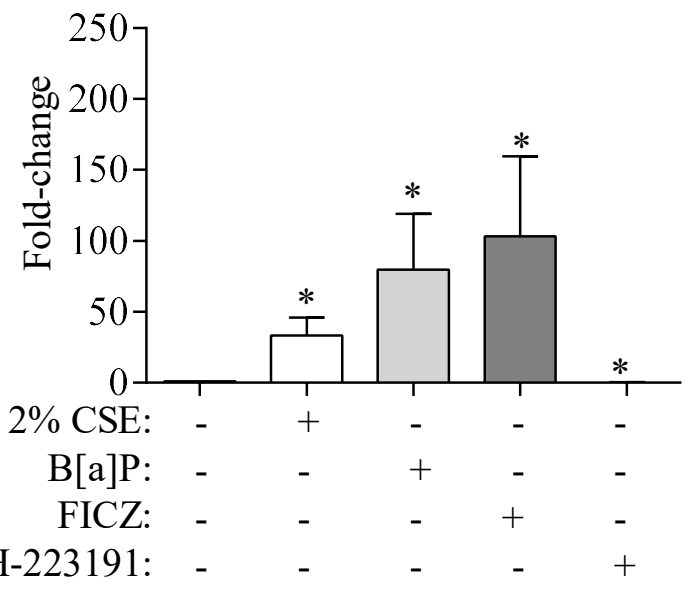

C. GADD34 mRNA- $6 \mathrm{hr}$

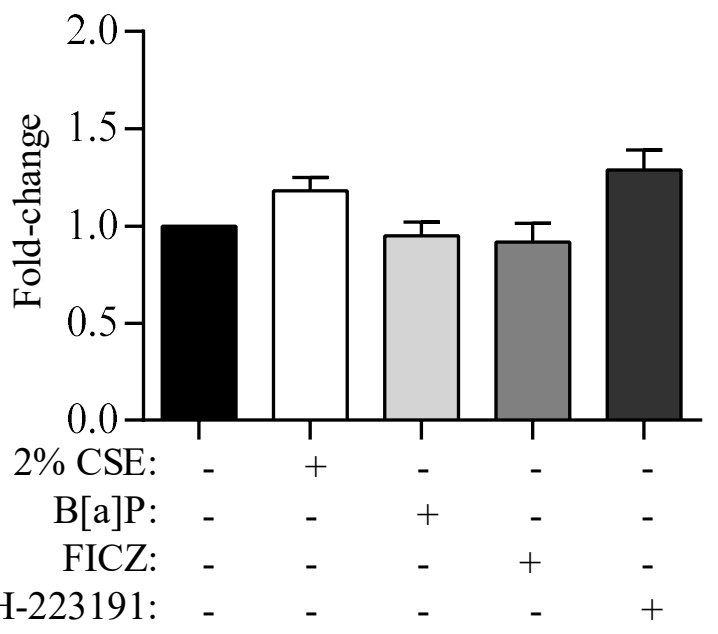

E. Atf6 mRNA- $6 \mathrm{hr}$

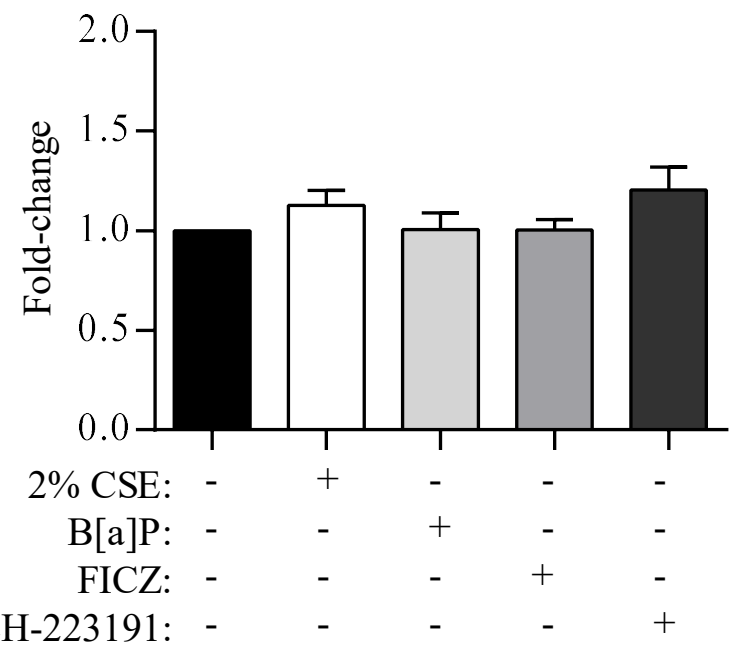

B. $G r p 78$ mRNA- $6 \mathrm{hr}$

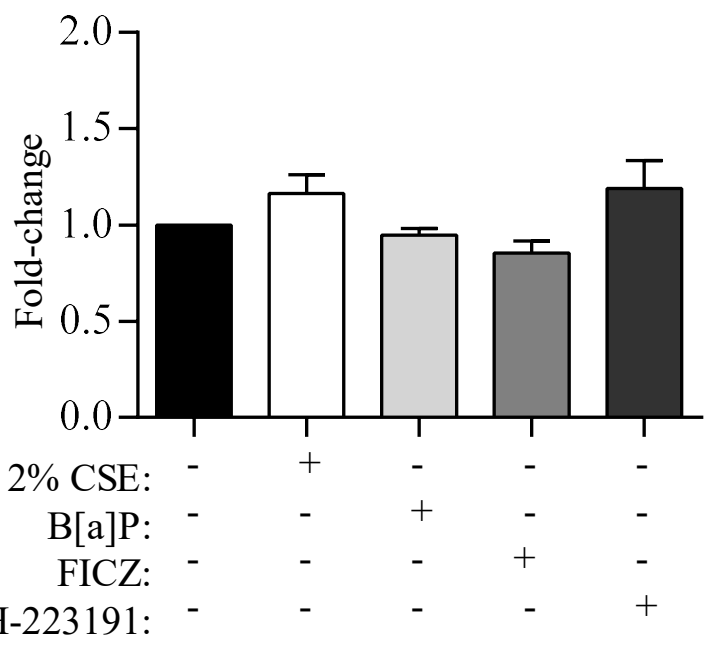

D. Atf4 mRNA- $6 \mathrm{hr}$

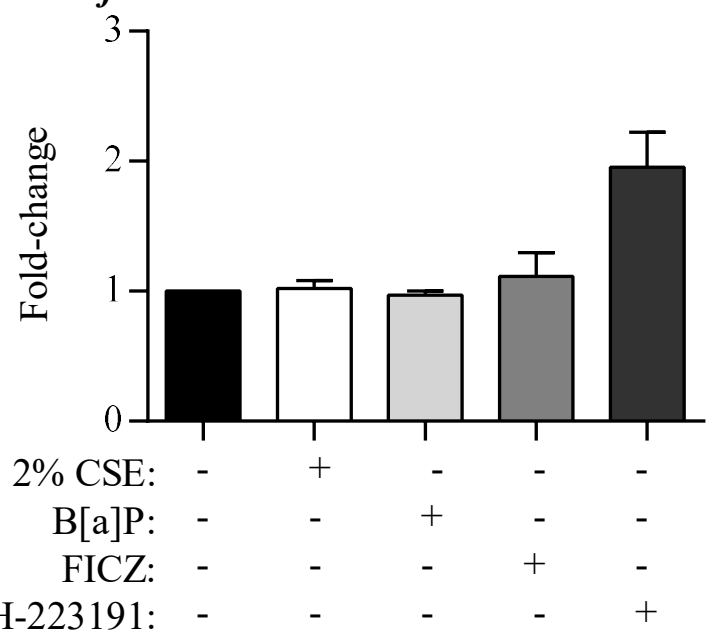

F. Chop mRNA- 6hr

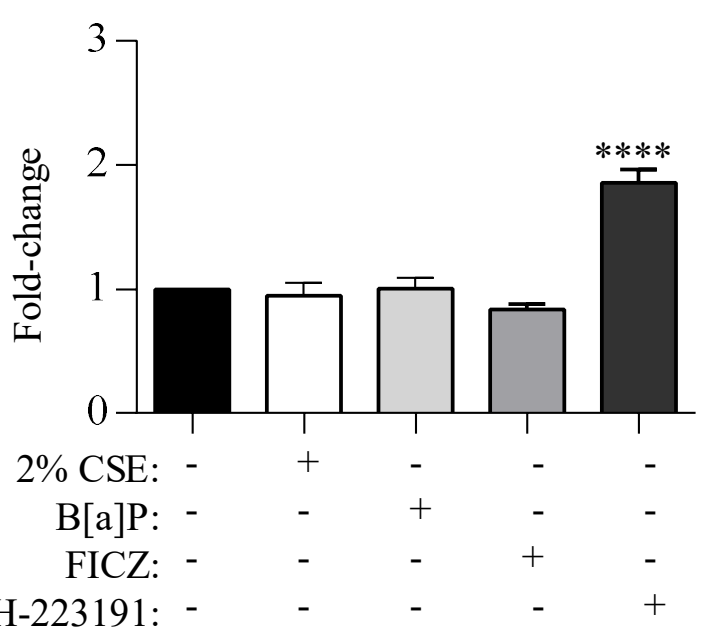


Figure S6

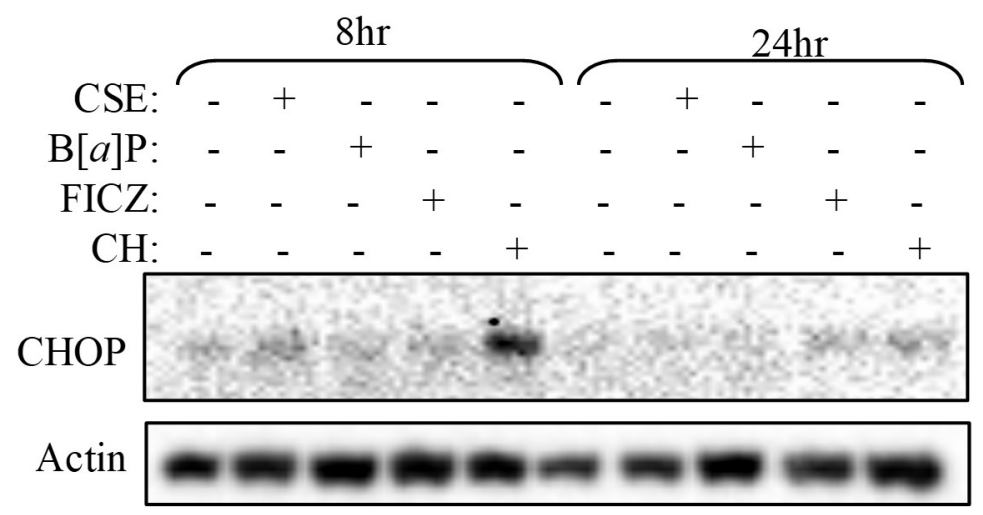


Figure S7

\section{mCyp1a1}

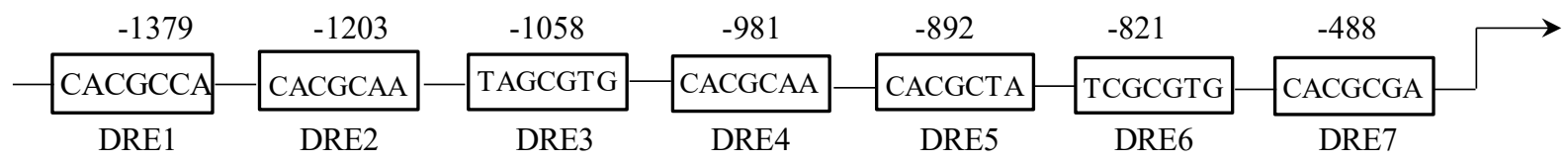

\section{hCyp1a1}

\begin{tabular}{|c|c|c|c|c|c|}
\hline-1383 & -1203 & -1058 & -984 & -896 & -488 \\
\hline CACGCCA & CACGCAG & TCGCGTG & CACGCAA & CACGCAA & CACGCGA \\
\hline DRE1 & DRE2 & DRE3 & DRE4 & DRE5 & DRE6 \\
\hline
\end{tabular}

mBecn1

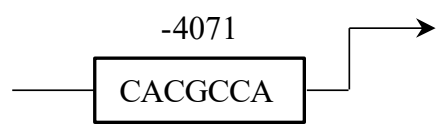

\section{hBecn1}

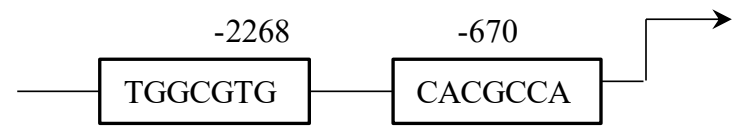

\section{$h L c 3$}

$\stackrel{-4176}{\longrightarrow} \stackrel{-2099}{\longrightarrow \text { TCGCGTG }}$

